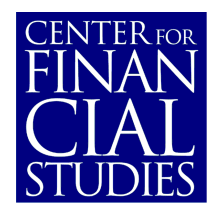

No. $2003 / 45$

\begin{abstract}
Nominal Exchange Rate Regimes and Relative Price Dispersion: On the Importance of Nominal Exchange Rate Volatility for the Width of the Border
\end{abstract}

Guenter W. Beck

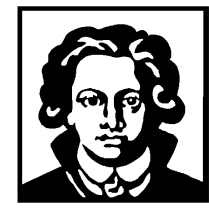

Center for Financial Studies 


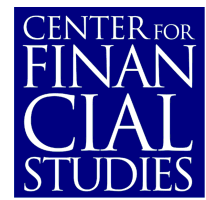

\section{Center for Financial Studies}

The Center for Financial Studies is a nonprofit research organization, supported by an association of more than 120 banks, insurance companies, industrial corporations and public institutions. Established in 1968 and closely affiliated with the University of Frankfurt, it provides a strong link between the financial community and academia.

The CFS Working Paper Series presents the result of scientific research on selected topics in the field of money, banking and finance. The authors were either participants in the Center's Research Fellow Program or members of one of the Center's Research Projects.

If you would like to know more about the Center for Financial Studies, please let us know of your interest.

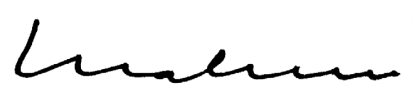

Prof. Dr. Jan Pieter Krahnen

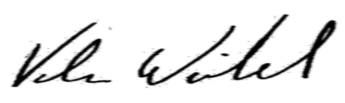

Prof. Volker Wieland, Ph.D.

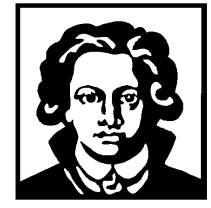




\title{
Nominal Exchange Rate Regimes and Relative Price Dispersion: On the Importance of Nominal Exchange Rate Volatility for the Width of the Border ${ }^{\dagger}$
}

\author{
Guenter W. Beck ${ }^{\dagger \dagger}$ \\ Goethe University Frankfurt and CFS \\ gbeck@,wiwi.uni-frankfurt.de
}

November 2003

\begin{abstract}
:
Based on a broad set of regional aggregated and disaggregated consumer price index (CPI) data from major industrialized countries in Asia, North America and Europe we are examining the role that national borders play for goods market integration. In line with the existing literature we find that intra-national markets are better integrated than international market. Additionally, our results show that there is a large 'ocean' effect, i.e., intercontinental markets are significantly more segmented than intra-continental markets. To examine the impact of the establishment of the European Monetary Union (EMU) on integration, we split our sample into a pre-EMU and EMU sample. We find that border effects across EMU countries have declined by about $80 \%$ to $90 \%$ after 1999 whereas border estimates across non-EMU countries have remained basically unchanged. Since global factors have affected all countries in our sample similarly and major integration efforts across EMU countries were made before 1999, we suggest that most of the reduction in EMU border estimates has been 'nominal'. Panel unit root evidence shows that the observed large differences in integration across intra- and inter-continental markets remain valid in the longrun. This finding implies that real factors are responsible for the documented segmentations across our sample countries.
\end{abstract}

JEL classification: F02, F40, F41

Keywords: Real exchange rate dispersion, real and nominal border effect, goods market integration, nominal exchange rate regime neutrality

\footnotetext{
${ }^{\dagger}$ I would like to thank Joachim Benner, Axel A. Weber and participants in a workshop at the European Central Bank for very helpful comments. This paper is part of a CFS research program on 'Local Prices and Aggregate Monetary Policy'. Financial support by the CFS is gratefully acknowledged. Part of the work on this project was completed while I was an intern at the European Central Bank. Of course, the author is responsible for any remaining errors.

${ }^{\dagger}$ Contact: Tel.: ++49-69-24294126. E-mail: gbeck@wiwi.uni-frankfurt.de
} 


\section{Introduction}

To infer the degree of integration across different goods markets, a large literature has relied on purchasing power parity (PPP)/the law of one price (LOOP). Based on the methodological approach, two major groups of studies can be classified: The first category of papers looks at the time series behavior of PPP/LOOP deviations, the second category compares within-country and cross-country relative price dispersion.

Using modern panel econometric techniques and data spanning long time periods to increase testing power, the studies of the first category arrive "at a surprising degree of consensus on a couple of facts" (?): First, they find that PPP/the LOOP holds, but only at the very long run. And second, they all point to very long half lives of PPP/LOOP deviations between three and five years. Similar results are obtained in the second category of empirical studies. Starting with the seminal paper by Engel and Rogers (1996), these papers show, that international relative price dispersion is significantly higher than intra-national relative price dispersion. Looking for the reasons of this so-called border effect, transaction costs, formal and non-formal trade barriers, the existence of nontradeable goods, pricing-to-market behavior and short-run price stickiness together with highly volatile nominal exchange rates are prominent candidates.

Due to data constraints most existing studies in this second category of literature include only very few (mostly two) countries. Furthermore, they usually employ different data sets. This makes it difficult to use them to directly compare the degree of integration across a larger set of markets. Such a comparison would require the use of a large and consistent set of price data for all included countries. While the integration of North American markets 1 has been studied intensively and also for Japan some evidence exists, ${ }_{2}^{2}$ the evidence for Europe is limited. Engel and Rogers (2001) and Hufbauer et al. (2001) are amongst the few who focus on European locations. Broader data sets that combine observations from more than one continent were employed by Engel et al. (1997) and Parsley and Wei (2001a) who use data from North America, Asia and Europe to study intra-national, intra-continental and intra-planetary deviations from the LOOP. In all of these studies only a few intra-national locations are used and the prime focus is on national data with cities being identified as the nations' capitals.

In this paper, we examine the importance of both distance and national borders between locations in determining the degree of the failure of PPP and the LOOP for a broad set of regional consumer price index (CPI) data from three continents. We make use of regional data available for nine U.S., twelve Canadian, twenty Japanese,

\footnotetext{
${ }^{1}$ See, e.g., Engel and Rogers (1996), Engel and Rogers (2000) or Parsley and Wei $(1996)$ for reference.

${ }^{2}$ See, e.g., Parsley and Wei (2001a) for reference.
} 
nine German, ten Austrian, five Finnish, twenty Italian, eighteen Spanish and seven Portuguese locations. For these 110 locations we are able to analyze movements of $5995(=110 * 109 / 2)$ relative prices. These data are taken from the SPATDAT databank, 3 which is by far the largest cross-regional data set used in this literature to date.

The use of this broad and consistent set of regional data allows us to directly compare the degree of integration across a large number of industrialized countries. We are particularly interested in the question how integration between North American countries compares to integration across European countries. Additionally, we want to examine whether we can identify 'ocean' effects, i.e., whether there are significant differences between intra-continental and inter-continental integration patterns. As our sample includes a number of European countries that adopted the euro in January 1999, we can also examine the impact of the introduction of the euro on the integration of its member countries 4 Any observed reduction of border effects across EMU member countries could basically be caused by three factors. These factors are: (i) globally effective factors such as an improvement of transportation technologies, (ii) the (exogenous) elimination of nominal exchange rate volatility and (iii) locally effective factors such as the elimination of formal and informal trade barriers in the context of the completion of internal market. Whereas the latter two groups of factors would have had an effect only on European border estimates, the first group of factors would also have affected our non-EMU border estimates. Thus, the inclusion of both EMU and non-EMU countries in our sample allows us to assess to which extent reductions in observed border effects across EMU countries were caused by either global or local factors. Since most efforts to harmonize conditions across EMU countries and to liberalize trade across them were made well before the introduction of the euro, we argue that most of the observed dynamic in European border effects is due to the exogenous elimination of nominal exchange rate volatility after January 1999.5 As Devereux and Engel (1998) show, such a 'nominal' integra-

\footnotetext{
${ }^{3}$ SPATDAT is a CFS databank with spatial consumer price data for regions/districts/cities from North-American countries (U.S., Canada, Mexico), South American countries (Argentina, Brazil, Bolivia and Columbia), European countries (Austria, Finland, Germany, Italy, Portugal, Spain and Switzerland), Asian countries (India, Indonesia, Japan, Korea, Malaysia, Philippines, Taiwan and Thailand) and 'Pacific' countries (Australia and New Zealand). Both aggregated CPI data and data for a large number of disaggregated categories of consumer goods have been collected.

${ }^{4}$ Similar work has been done by Parsley and Wei (2001b), Engel and Rose (2002) and Beck and Weber (2001). Unlike our work, the studies by Parsley and Wei (2001b) and Engel and Rose (2002) are based on national data only. Beck and Weber (2001) also use regional European data. However, they have only eighteen months of data available for the EMU period (from 1999.01 - 2001.06). Additionally, their data set is considerably smaller with respect to the regional coverage.

${ }^{5}$ Additionally, evidence on the impact of free trade arrangements on integration (see Engel and Rogers (2000) and Rogers and Smith (2001) for corresponding evidence) provides no or only weak support of an integration effect of such arrangements.
} 
tion effect is not necessarily welfare-improving.

Following Engel and Rogers (1996) and Engel and Rogers (2001) our estimation equations use a measure for the integration of markets as the dependent variable and examine whether a national border between two markets plays a significant role for the integration between these two markets. In addition to a border dummy the right-hand side variables include several other possible explanatory variables such as the distance between two locations and a measure for nominal exchange rate volatility. When the overall available sample period (1991.01 - 2002.12) is considered our result show that most of the failures of PPP/the LOOP are attributable to currency volatility in conjunction with rigid nominal prices, but other barriers are also important explanatory factors. We find that, even taking into account nominal exchange rate variability, distance between cities and the border continue to have positive and significant effects on real exchange rate variability. In the words of Devereux and Engel (1998) this shows that observed border effects are largely 'nominal' and only a smaller part is 'real'. We also show that there are large 'ocean effects', i.e., the degree of integration across intra-continental markets is much higher than that of inter-continental markets. Additionally, our estimation results indicate that including nominal exchange rate volatility in a multi-country setting to control for the effect of currency volatility on observed border estimates is problematic as it can lead to a bias in the estimates of other variables.

When we split the sample into a pre-EMU and an EMU subperiod, we find that border estimates across EMU member countries drop drastically (by around $80 \%$ to 90\%) after January 1999. However, also in the EMU, border estimates remain highly significant across all countries. As nominal exchange rate volatility has been extinguished across the EMU member countries these results indicate that real factors play an important role for market integration. Using the metric of Engel and Rogers (1996), our basic measure for relative price dispersion suggest a 'real' width of European borders of around 5,700 miles. To our knowledge, this is the first study that examines border effects in an international context "without trade barriers or currency fluctuations" (Parsley and Wei (1996)). When comparing the dynamics of EMU with non-EMU border estimates, we find that the large reduction of EMU border estimates is not accompanied by a comparable reduction of non-EMU border estimates. Thus, we can rule out that globally effective factors have led to the strong reduction in EMU border effects. Given our settings, results strongly suggest that observed reductions are mostly a consequence of the exogenous elimination of nominal exchange rate volatility, i.e., EMU has had a strong 'nominal', but only a small 'real' effect on the width of its borders. Concerning the large differences in the pattern of integration of intra-continental and inter-continental markets, the analysis of subperiods suggests that oceans have become wider rather than closer. 
Do these integration patterns remain valid in the long-run when prices adjust to their equilibrium values and thus the impact of nominal exchange rate volatility on relative price behavior declines? To shed some light on this question, we apply unit root analysis to the large sample of intra- and international relative price series included in our sample. If observed differences in estimated border effects were solely caused by short-run sticky prices in conjunction with nominal exchange rate volatility, we would expect them to vanish or at least drastically mitigate. The results from our panel unit root analysis show that this is not the case: Differences in integration across intra-continental and inter-continental markets remain valid even when a long-run perspective is taken. This suggests that oceans make 'real' contributions to the width of borders.

The rest of the paper is organized as follows. In the next section, we will describe our data set of regional European, North American and Japanese CPI data. In section 3, we use these data to make inference on the size of border effects within Europe, within North-America, between Europe and North-America, between Europe and Japan and between North-America and Japan. We will compare all results to the existing literature. We will also provide evidence on subcategories (food, etc.). In section 4, we separate our overall sample to make inference on the dynamic behavior of the border effects. This allows us to assess whether integration between the considered markets has increased in the 1990s (as the discussion on globalization would suggest). Additionally, we will use our results to draw conclusions about the size of the 'nominal' border effect. Section 5 performs some robustness checks. Then, in section 6, we focus on long-run real exchange rates and provide estimates on half-lives from PPP deviations for European, North-American and Japanese real exchange rates. Section 7 concludes.

\section{Data and Descriptive Statistics}

Based on deviations from PPP/the LOOP, this paper examines the degree of integration of national and international goods markets. Ideally, absolute prices of identical goods from different locations should be used for this purpose. However, the availability of such data is very limited. Therefore only few studies 6 actually use absolute price data, whereas most studies rely - as we do - on price index data. A major drawback of the studies that use absolute prices is that they are generally limited with respect to the length of the time period for which data are available. Moreover, most of these data stem from private sources, have many missing observations and suffer from a lack of representativeness. Furthermore, absolute price

\footnotetext{
${ }^{6}$ See, e.g., Parsley and Wei (1996), Parsley and Wei (2001a), Parsley and Wei (2001b), Crucini et al. (2000) or Goldberg and Verboven (2001).
} 
data are usually available at a national level only. This study, however, takes a regional perspective to enable an assessment of the importance of national borders for goods market integration. Although it is cumbersome, compiling a consistent set of aggregate and disaggregated regional price index data is possible.

In this paper, we use regional data from three continents. A detailed list of the countries and the respective regions included in the analysis is given in table 1. As one can see there, we include a total of 110 regions/cities that are members of one out of nine countries. In terms of continents, we have included 29 North American regions (from the U.S.A. and Canada), 20 Asian regions (from Japan) and 61 European regions/cities (from Germany, Austria, Finland, Italy, Spain and Portugal). All data are obtained from official statistical sources, thus data integrity should not be a major concern. Total index data are generally available for the period from January 1991 up to December 2002. 7 Data for subcategories generally start in January 1995 and end in December 2002.8 Despite the restricted availability of disaggregated data at a regional level and even after taking into account different classification schemes across countries we were able to construct seven relatively homogeneous subcategories of goods. These include food (food), alcoholic beverages (alco), clothing and footwear (clot), shelter (hous), household furnishings and operations (furn), medical care (heal) and transportation (tran).9 Table 2 gives an overview on which of the national subcategories we used for constructing our data. In most cases, existing national categories provide a satisfactory match across countries whereas for some few categories (shelter in the U.S. case and household furnishings in the Canadian case) new categories had to be constructed. In the latter cases, the respective national CPI weights were used.

To get some intuition on our data we computed some descriptive statistics that we report in table 3. This table contains results for the mean and standard deviation of our basic measure of relative price dispersion. Following Engel and Rogers (1996), goods market integration between region $i$ and region $j$ is computed as the standard deviation of two-month changes in relative prices between the two regions. Thus, our measure for integration, $V\left(q_{i j}\right)$, is given by

$$
V\left(q_{i j}\right)=\sqrt{\operatorname{var}\left(\Delta q_{i j, t}\right)}
$$

where $\Delta q_{i j, t}$ denotes the two-month changes between region's $i$ and region's $j$ relative price and $\operatorname{var}($.$) denotes the empirical variance of \Delta q_{i j, t}$. To see why this is an

\footnotetext{
${ }^{7}$ Finnish data start in January 1995 and Japanese data end in April 2001.

${ }^{8}$ For Austria and Japan, no data on subcategories are available. Canadian data end in April 2001.

${ }^{9}$ Terms in brackets denote the short terms that are used for the respective category in tables and graphs.
} 
appropriate measure let us refer to the existing empirical literature on real exchange rate convergence. From this literature we know that real exchange rates are very persistent and that it is hard to reject the null hypothesis of a unit root (stochastic trend). One potential explanation for trending behavior in real exchange rates is the existence of nontradeable goods in conjunction with productivity growth differentials (between the traded and nontraded goods sectors) across regions. Thus, real exchange rates can be seen as (near-)unit root processes and it is plausible to characterize the real exchange as being composed of a nonstationary and a stationary component, i.e.,

$$
q_{i j, t}=v_{i j, t}+u_{i j, t}
$$

where $v_{i j, t}$ is a nonstationary process and $u_{i j, t}$ is a possibly serially correlated, mean zero innovation term. This latter term can be considered to be the 'transitory' component of the real exchange rate. Its mean reverting (stationary) behavior can be thought of as being caused by arbitrage forces. Thus, the behavior of $u_{i j, t}$ gives us the necessary information on the integration of two markets. In the case of perfect integration this term should be zero or at least very close to zero. If there are, however, obstacles to integration such as transportation or information costs then larger deviations from zero can occur and then there might exist a 'band of inactivity' around zero in which no arbitrage occurs. The width of this band is negatively related to the integration across the respective markets. Thus, the volatility of $u_{i j, t}$ is a good candidate for measuring integration as it can capture the size of this band of inactivity. 10

Starting with the results for PPP deviations (i.e., the results for the total index) we can see that the average overall dispersion $\left(32.83 * 10^{-3}\right)$ is spread considerably across three different groups. These groups are intra-national, intra-continental and inter-continental region pairs. The first group consists of all relative prices between regions that are in the same country. The second group consists of relative prices between regions that are in different countries but are on the same continent whereas the third group consists of international relative prices between regions that are located in different continents. Intra-national price dispersion is relatively low $\left(3.78 * 10^{-3}\right)$, intra-continental dispersion is four times larger and inter-continental is more than ten times larger than intra-national dispersion and three times larger than intra-continental dispersion. Whereas the results for intra-continental region pairs already clearly indicate the existence of a border effect, the results for intercontinental region pairs show that this effect is even larger when an ocean is between the respective countries. This provides the motivation for our question in the next section: "How Wide is the Atlantic/Pacific?" While the dispersion across these three

\footnotetext{
${ }^{10}$ In section 5 , we will consider alternative measures for integration that confirm our findings from this and the next two sections.
} 
regional groups is large, dispersion within each group is surprisingly low (between $1.58 * 10^{-3}, 5.68 * 10^{-3}$ and $9.81 * 10^{-3}$ which is considerably smaller than the value for the total group $\left.\left(20.31 * 10^{-3}\right)\right)$. Thus, intra-national, intra-continental and intercontinental relative prices constitute relatively homogeneous groups.

From an economic point of view, there are several possible explanations for this finding. As the distance between regions within the same continent is usually smaller both transportation and information costs between regions of the same continent are lower. Then the band of inactivity caused by these two factors is also smaller and dispersion will be lower. Another explanation can be that labor markets in countries that are member of the same continent are more integrated and thus production costs and therefore prices of nontradeable inputs will be less dispersed in these countries than in countries that lie on different continents. Alternatively, the degree of monopoly power and thus the degree of pricing to market can be higher across countries of a different continent than across countries of the same continent. An additional factor that might explain our results is the role that short-run sticky prices in conjunction with nominal exchange rate volatility plays. A more systematic investigation of the impact of some of these factors is deferred to the next section. Looking at subcategories we find the same order of dispersion for each category: The dispersion is lowest for intra-national region pairs, it is considerably higher for intra-continental relative prices and is even higher for inter-continental prices. Within each of these groups, however, the dispersion is relatively homogeneous. When trying to assess whether there is a significant distinction in relative price behavior between tradeable and nontradeable goods it is more or less impossible to find any difference. This is confirmed when looking at the summary statistics for both groups at the bottom of table 3. Contrary to our intuition that tells us that dispersion should be lower for more traded goods categories we find that it is actually higher for these categories. However, there is a relatively straightforward for this finding: As our data represent relatively highly aggregated categories, all categories contain large shares of both tradeable and nontradeable goods. Only the relative size of both components differs across categories. This is probably one of the main reasons why much of the literature finds only very weak evidence in favor of the hypothesis that the LOOP is more valid for tradeable goods.11 Following Engel and Rogers (1996), we thus do not longer differentiate between traded and nontraded goods in the following but use all categories equally. In the next section, we will examine the size of border effect across the member countries of our sample and we will shed some light on potential explanatory determinants.

\footnotetext{
${ }^{11}$ See, e.g., Canzoneri et al. (1999) for corresponding evidence.
} 


\section{How Wide is the Atlantic/Pacific? Evidence on the Border Effect from European, North American and Japanese Regions}

In the last section we saw that the dispersion of relative prices shows a very interesting pattern: We confirmed previous evidence that international dispersion is much higher than intra-national dispersion. But when we compared intra-continental with intercontinental dispersion we could see that international price dispersion itself is very heterogeneous. In this section, we will examine this issue more analytically.

\subsection{The Estimation Approach}

A graphical illustration of our estimation approach is given in figure 1 where we plot our measure of relative price dispersion against the (log of) distance between the respectively considered regions. 12 Figure 1 visualizes the three different groups of relative price dispersion that we identified in the last section: There is a very homogenous 'low-dispersion', a little more heterogeneous 'medium-dispersion' and a relatively homogeneous 'high-dispersion' group. As we saw in table 3 , these three groups correspond to the intra-national, intra-continental and inter-continental relative prices. As the upward sloping line plotted for the group of intra-national relative prices shows distance seems to play an important role for price dispersion: There seems to be a positive relationship between distance (which we use as a proxy for information and transportation costs) and disintegration of markets. To examine the effect of distance (and other potential explanatory factors), we run regressions of the following form:

$$
V\left(q_{i j}\right)=\sum_{k=1}^{l} \beta_{k} * x_{i j, k}+\text { regdumm }+\epsilon_{i j},
$$

where the term $V\left(q_{i j}\right)$ denotes our measure of relative price volatility as defined in the previous section. The variables $x_{i j, k}$ represent the explanatory variables, the estimated coefficients $\beta_{k}$ denote the impact of variable $x_{i j, k}$ on relative price volatility (and therefore on the degree of disintegration), regdumm represents regional dummy variables. $e_{i j}$ is assumed to be a mean-zero innovation term. Regional dummies are included to control for idiosyncratic characteristics of the included regions. To control for potential heteroskedasticities in error terms we use White's heteroskedastic-consistent standard errors to compute test statistics.

\footnotetext{
${ }^{12}$ The distance between regions is computed as the great circle distance using latitude and longitude data obtained from the webpage: http://www.astro.com/atlas.
} 


\subsection{Results for Total Index}

Following Engel and Rogers (1996), our first candidate variable to explain relative price dispersion across regions is distance. Distance is used as a proxy for 'transaction' costs of goods arbitrage that involve transportation and information costs for which data are usually not available. As shown in the literature, 13 transaction costs of arbitrage can generate a band around the PPP/LOOP equilibrium value within which no arbitrage occurs. Formally, this can be expressed as

$$
-c_{i j}<q_{i j}<c_{i j}
$$

where the term $c_{i j}$ represents the costs of arbitrage between region $i$ and region $j$. As transaction costs are likely to depend positively on the distance between two markets we assume a positive relationship between $c_{i j}$ and distance. As we do not think this relationship to be proportional (or even convex) but concave, we assume $c_{i j}$ to depend on the $\log$ of distance, i.e., $c_{i j}=c_{i j}(\ln d i s t)$. The results for this specification are reported in column two ('Spec. 1') of table 4. The estimated coefficient for distance $\left(13.63 * 10^{-3}\right)$ is of the assumed sign and is highly significant. Thus, distance significantly contributes to real exchange rate dispersion across regions.

To see whether transaction costs alone can explain relative price dispersion or whether national borders matter for integration we include a border dummy in our regression. This variable takes the value 1 when the two considered regions are located in different countries and takes the value 0 otherwise. A significant value for this border dummy indicates that national markets are more integrated than international markets. The results are presented in column three ('Spec. 2') of table 4. The estimated coefficient for the border dummy $\left(13.84 * 10^{-3}\right)$ is positively significant indicating that being located in different countries considerably contributes to real exchange dispersion. This result confirms previous findings in the literature that national markets are much better integrated than international markets. After including the border dummy the impact of distance is reduced, but remains highly significant.

What are possible determinants of this border effect? One of the most promising candidates is nominal price stickiness in conjunction with volatile nominal exchange rates. When prices are sticky in the short-run then the volatility of relative prices is equal to the volatility of the nominal exchange rate, i.e., $\sqrt{\operatorname{var}\left(\Delta q_{i j, t}\right)}=$ $\sqrt{\operatorname{var}\left(\Delta s_{i j, t}\right)}$, where $s_{i j}$ denotes the nominal exchange rate between region $i$ and region $j$. As Mussa (1986) and others have shown there are clear indications that short-run real exchange rate behavior is dominated by nominal exchange rate behavior. Thus, we expect nominal exchange rate variability (n.e.r.vol.) to have a large

\footnotetext{
${ }^{13}$ See Davutyan and Pippenger (1990) and Dumas (1992) for examples.
} 
impact on real exchange dispersion. It will be interesting to see, however, whether the full border effect will vanish or whether there will still be some remaining effect. In the first case, the border effect would be a completely 'nominal' effect whereas in the second case the border effect would consist of a 'nominal' and a 'real' part. The results for this specification are reported in column four ('Spec. 3') of table 4 . As we suggested, nominal exchange rate volatility has a considerable impact on real exchange rate dispersion. The coefficient is positively significant and its size (close to one) indicates that short real exchange dispersion is largely caused by nominal exchange rate movements. The implications of the inclusion of nominal exchange rate volatility on the distance coefficient and the border dummy are considerable: The distance coefficient remains positive and significant, but drops drastically in value (from $10.49 * 10^{-3}$ to $0.35 * 10^{-3}$ ). Even more drastic are the consequences for the border dummy. It not only reduces its value but reverses its sign. It is now significantly negative $\left(-1.80 * 10^{-3}\right)$. These results imply a positive 'nominal' border effect and a negative 'real' border effect. Thus, crossing the border would - after controlling for distance and nominal price stickiness in conjunction with exchange rate volatility - lead to lower relative dispersion. This result is counter-intuitive and needs further exploration. To obtain the results in table 4 , all bilateral border variables and the coefficient for bilateral nominal exchange rate volatility are forced to be equal. However, as we know from experience and as we have seen from the descriptive statistics, we have good reasons to assume that both border effects and the impact of nominal exchange rate volatility on relative price dispersion might be very heterogeneous across country groups. Forcing these largely varying effects to be equal can lead to biases in our estimates.

To underpin this intuition we include an intra-continental dummy ('Spec. 4' of table 4) into our basic regression that is supposed to control for heterogeneities in border effects across countries. The results fully confirm our intuition. The value of the coefficient on the nominal exchange rate volatility drops (from 0.94 to around 0.90), the border coefficients becomes positive and the added dummies for intracontinental pairs is strongly negatively significant. The results from 'Spec. 3' and 'Spec. 4' show that including nominal exchange rate volatility in a regression to explain relative price dispersion does not necessarily 'identify' the 'real' border width but might lead to biases in estimated coefficients instead.

In this paper, we are using a different strategy instead. By referring to the EMU experience where nominal exchange rate volatility across countries was extinguished in January 1999, we are able to unambiguously identify the 'real' width of the border. As a preliminary exercise to this attempt and to get some intuition on the heterogeneity in border effects across our sample countries we decompose our border dummy in a set of individual bilateral border dummies. While this approach has 
the disadvantage that we can no longer control for nominal exchange rate volatility (as this variable would be fully collinear with the individual border dummies) it will turn out to be useful when we are trying to assess the implication of the exogenous elimination of nominal exchange rate volatility for border effects in the next section. Summary results for individual border estimates (both when Finnish data are included and not included) are given in table 5, the detailed results (for the case that Finnish data are included) are given in table $\mathrm{A}$ of appendix $\mathrm{A}$. As is clear from the detailed results, all results confirm our intuition: All border dummies are significantly positive, the distance coefficient is positive and remains significant even after controlling for individual borders. The summary results in table 5 show for the long sample (1991.01 - 2002.12) the following integration order of international goods markets: Intra-national markets are best integrated, followed by NAFTA countries that are in turn better integrated than EMU countries, and inter-continental country pairs (where EMU markets versus NAFTA markets are better integrated than both of these versus Japan). The shorter sample shows a strong decrease in the average border estimate for EMU markets, all other results are basically unchanged.

\subsection{Results for Subcategories}

One drawback of the results shown above is that they are based on real exchange rates computed from the total CPI index. The high share of nontradeable components in this index make it a sub-optimal candidate for the study of integration of markets. As arbitrage does not force prices of nontradeables to be equal across markets an index that contains a high portion of nontradeable goods is only a second-best variable for our purposes. As we do not directly use the relative price but its deviation from a stochastic trend some of these objections are accounted for. However, there is another - preferable - way. Instead of using the total index one could use absolute prices of tradeable goods (that we do not have available) or disaggregated CPI data. As outlined in section 2, we constructed seven subcategories that are relatively consistent across the considered countries.

The outcomes of our estimations are reported in table 6. As one can see, there are some similarities in the pattern of the results across subcategories. For all categories, we have a positive and in most cases significant impact of transaction costs (distance) on the dispersion of relative prices. For all categories, either EMU or NAFTA borders are smallest, whereas EMU-NAFTA estimates are always considerably higher. The individual average border estimates, however, vary considerably across categories: While for NAFTA pairs they are all in the range between 7.91 and 12.43, they vary between 5.99 (furn) and 27.17 (clot) for EMU pairs. In the last row, we report average distance and border results for all categories. Comparing estimated average border effects, the results show that markets across European 
countries seem to be slightly less integrated than North American markets.

Following the metric developed by Engel and Rogers (1996) we can get some insight into the relative importance of borders relative to transaction costs by computing the ratio of average border estimates to average distance estimates. However, before doing so some caveats are to be mentioned: Firstly, our distance variable is used as a proxy for transaction costs of arbitrage. This proxy is only valid when the relationship between distance and transaction costs indeed exists and is of the form (log-linear) that we are suggesting. If this is not the case our measure of the 'width' of the border might over- or underestimate the relative importance of the border. Secondly, as even Engel and Rogers (1996) emphasize, the implied border widths from the chosen log-linear distance specification are very sensitive to even minor changes in estimated coefficients both for the border and/or distance. Parsley and Wei (2001a), e.g., find that the U.S.-Japanese border has a width of 43 trillion miles which is certainly irrealistic. Nevertheless, we think that a comparison of the relative importance of estimated distance and border coefficient provides useful insights in the working of international goods markets. Therefore, we will stick to the Engel-Rogers border metric keeping in mind its deficiencies. When the border width is computed on the basis of all categories, we obtain a border width for EMU of $10.65 * 10^{6}$ $(=\exp (10.49 / 0.63) / 1.6)$ miles, for NAFTA of $2.11 * 10^{6}(=\exp (9.47 / 0.63) / 1.6)$ miles for inter-continental border of $6.73 * 10^{20}(=\exp (30.51 / 0.63) / 1.6)$ miles.

\section{Looking at Subperiods: EMU and the Dynamics of Intra- and Intercontinental Border Effects}

\subsection{The Description of our Approach}

There has been a considerable discussion in international economics concerning the causes of the increased volatility in real exchange rates after the breakdown of the Bretton Woods System. One group of economists (Stockman and co-authors are amongst these) argue that real factors are responsible for the increased volatility of both nominal and real exchange rates. According to their view, the real exchange rate is nominal exchange rate regime neutral. This view is heavily doubted by the other group of economists (to which - amongst others - Mussa belongs). They argue that prices are sticky in the short-run and thus the real exchange rate is determined by the nominal exchange rate in the short-run. In this section, we will contrast the dynamics of European border effects before and after the introduction of the euro with corresponding evidence of non-EMU border effects for the same time period. In doing so, we will provide some evidence in favor of the second view. To examine the question whether relative price dispersion is mainly caused by real factors 
(as the first group would state) or by short-run price stickiness in conjunction with volatile nominal exchange rates (as the proponents of the second group would state), we employ the introduction of the euro to construct a 'quasi-experimental' design. We split the relative prices of our sample into two groups that we call 'treatment' and 'control' group. The 'treatment' group consists of all EMU international relative prices whereas the 'control' group consists of all other (non-EMU) international relative prices. The 'treatment' that the EMU group but not the 'control' group experiences is the exogenous elimination of all nominal exchange rate volatility in January 1999. According to our design, both groups experience the impact of all other global (real) factors in a more or less similar way. We are aware that this latter assumption is simplifying insofar as the considered groups are too different to allow us to make this assumption. For example, it is highly probable that the enormous efforts of harmonization made by EMU countries have had considerable positive effects on the real border width. As there haven't been comparable efforts between the U.S.A. and Canada, any observed reductions in EMU border effects that are not present for NAFTA could not be uniquely assigned to the elimination of nominal exchange rate volatility. Whilst this is a generally valid argument, there are still at least two arguments that weaken it. First, in the context of trade liberalization, also considerable efforts to foster trade and eliminate trade frictions have been made between non-EMU countries. Secondly, and more importantly, most efforts to harmonize conditions across EMU countries and to liberalize trade were made at the beginning of the nineties and not after the introduction of the Euro. So, these efforts must have been effective before the introduction of the euro.

To implement the approach we split the available data into subperiods and study the change in estimated border coefficients. Besides looking on the impact of the EMU on intra-EMU relative prices this approach allows us to study the evolution of all non-EMU international border estimates. We begin by reporting results for the total index and then turn to subcategories.

\subsection{Results for Total Index}

For the total index, our data span the period from January 1991 to December 2002. To study the evolution of integration over time, we split the total sample into three subperiods: 1991.01 - 1994.12, 1995.01 - 1998.12 and 1999.01 - 2002.12. The first of this subperiods includes the ERM crisis but is also characterized by considerable efforts of trade liberalization (first stage of EMU (completion of the internal market)). The second subperiod does not include any crisis but is mainly characterized by EMU member countries to achieve the Maastricht criteria. In this period, EMU countries experienced considerable convergence in inflation rates, nominal exchange rate volatility was relatively slow. In January 1994, NAFTA came 
into place and led to an elimination of most tariffs between the U.S.A. and Canada. Our third subperiod is the EMU period that is characterized by the elimination of national currencies (and thus nominal exchange rate volatility) of all EMU countries. The estimation results for these three subperiods are reported in table 7. In this table we report estimated coefficients for (the log of) distance and summary results for individual border estimates that we grouped together as in the previous section. All three subperiods show some commonalities: First, the distance coefficient is always positive and - except for the second subperiod - statistically significant. In other words, transaction costs seem to play an important role and this role does not tend to diminish over time. Secondly, border estimates are generally significant in all three subperiods, i.e., intra-national markets are better integrated than international goods markets throughout the sample period. With respect to the evolution of the size of estimated border effects, we can, however, observe interesting patterns. As the results show, for all border estimates apart from EMU values only slight changes occur. The NAFTA coefficient, e.g., changes from $11.36 * 10^{-3}$ in the first subperiod to $11.92 * 10^{-3}$ in the second subperiod and further increases to $12.41 * 10^{-3}$ in the EMU period. Similarly, some increases in average border estimates are found for 'EMU-JA' and 'NAFTA-JA', whereas estimates for 'EMU-NAFTA' show some decrease in value. Although some of these changes are of some importance, they are relatively small compared to the dynamics that we observe for the average EMU estimates. While there is only a slight change between the first and second subperiod, there is a dramatic reduction (by around 85\%) between the second and the third subperiod for the EMU coefficient. These estimates confirm previous findings by Beck and Weber (2001) who consider a shorter period and whose sample does not include Finnish data. This finding has two interesting aspects. First, given our 'experimental design', we have some certainty that the observed reduction is almost exclusively due to the elimination of the 'nominal' part of the border effect, i.e., due to the elimination of nominal exchange rate volatility that caused - in conjunction with sticky prices - a considerable dispersion in real exchange rates. Secondly, EMU borders still matter for real exchange rate dispersion. In other words the remaining border effect is a 'real' border effect that is detrimental to welfare as it distorts the efficient allocation of resources across national markets. Unlike in the previous section (and unlike all comparable studies that did not use EMU data) we are certain to have identified the 'real' border effect. A graphical illustration of our results that nicely elaborates the differences in the evolution of estimated border coefficients is given in figure 2. There, we plot the estimated individual border effects for the pre-EMU period (1995.01-1998.12) on the y-axis and those for the EMU period (1999.01-2002.12) on the x-axis. As one can clearly see, all non-EMU estimates are along (or even slightly above) the $45^{\circ}$ degree line. All EMU estimates on the other 
side move drastically towards the $\mathrm{x}$-axis. They are, however, still above the $\mathrm{x}$-axis, indicating that EMU-borders still matter for relative price dispersion and that EMU international markets still behave differently from EMU intra-national markets.

\subsection{Results for Subcategories}

For the subcategories, neither Japanese nor Austrian data are available. Additionally, the data only start in January 1995. Thus, we are considering only two subperiods in this subsection. The first subperiod (the pre-EMU period) is from 1995.01 1998.12, the second subperiod (the EMU period) is from 1999.01 - 2002.12. Following the same estimation strategy as for the total index, we obtain results that are presented in table 8. Our findings for the first subperiod show the same structure as we found for the total period: Distance is mostly positively significant, border estimates are lowest for NAFTA, followed by EMU pairs and EMU-NAFTA pairs. Distance seems to be a little less important for nontradeable goods, there is, however, no really clear distinction to be made in estimated coefficient based on whether goods are tradeable or not. For the EMU period, we get results that are similar to those for the total index: Non-EMU border estimates do not change much. As table 9 shows, the average NAFTA border estimate increases slightly from $7.66 * 10^{-3}$ to $10.83 * 10^{-3}$, the corresponding EMU-NAFTA estimate increases from $28.96 * 10^{-3}$ to $32.08 * 10^{-3}$. The EMU estimate, however, almost cuts into half as it drops from $13.05 * 10^{-3}$ to $6.93 * 10^{-3}$. The implied 'width' of the EMU border reduces from $2.30 * 10^{11}$ miles to 'only' 5, 701 miles. Engel and Rogers (1996) who used their estimates to make inference on the width of the U.S.-Canadian border found - based on all goods categories - a border width of 75,000 miles which is 15times larger than our estimates. However, as we have pointed out above, their results reflect the size of the 'real' and the 'nominal' border. As the nominal exchange rate between the U.S.A. and Canada is not fixed, Engel and Rogers (1996) are not - as we are - able to make inference on the 'real' width of the border alone.14 As no computation of the 'real' width of the U.S.-Canadian border is possible, a direct comparison is impossible. The relatively small figures for the total border effect (that is much lower than the corresponding pre-EMU value for EMU-countries) indicate, however, that the 'real' U.S.-Canadian border width might be lower than that for EMU countries.

\section{Some Sensitivity Analysis}

In the last two sections, we were able to isolate the 'real' part of EMU border effects from the 'nominal' part. Additionally, we demonstrated the impact of nominal

\footnotetext{
${ }^{14}$ Although they make some efforts to do so.
} 
exchange rate volatility on real exchange rate dispersion. In this section, we provide evidence on the robustness of these results with respect to the employed measure for integration. To see how sensitive our results are with respect to the measure used in the analysis, we report results for two other measures of relative price dispersion in this section.

\section{$5.1 \quad$ Volatility Measure 2}

One potential shortcoming of our basic measure of integration is that standard deviations are relatively sensitive with respect to outliers. A better measure for price dispersion in the presence of outliers might be given by the spread between the 10th and the 90th percentile of the distribution of two-month relative price changes. Basic results for this measure are reported in tables 10 and 11. Table 10 presents results when total index data are used. Entries in the upper panel ('Specifications 1 to 4') correspond to entries in table 4, whereas entries in the lower panel ('Individual Border Estimates') represent results for subperiods corresponding to entries in table 7. As one can see, the basic structure of the results from the previous section remains valid. Outcomes for specifications 1 to 4 confirm the findings for our basic measure: Distance (and thus transaction costs of arbitrage) plays a significantly positive role. However, its influence is much smaller than that of the border. The most prominent role, however, is played by nominal exchange rate volatility. As in the previous case, when nominal exchange rate volatility is included, the border dummy variable turns negative. This effect vanishes when we control for heterogeneity across exchange rates (specification 4 ).

For the subperiods, we can also confirm our previous findings. While the size of the border coefficients does not significantly diminish for non-EMU pairs, it falls by around $921 \%$ (from $69.72 * 10^{-3}$ to $6.42 * 10^{-3}$ ) for EMU borders. Again this coefficient gives us the 'real' part of the border effect. Additionally, the abrupt drop in real exchange rate dispersion after the introduction of the euro in conjunction with relatively unchanged real exchange rate dispersion across non-EMU regions shows that most of the border effect is caused by nominal effects.

Results for subcategories are presented in table 11 and basically mirror corresponding findings from our basic specification. Distance is generally positively significant; in the first subperiod, borders matter most for EMU-NAFTA pairs, followed by EMU and NAFTA pairs. Again, border estimates do not change significantly across subperiods for NAFTA and EMU-NAFTA pairs but drop drastically for EMU pairs. As table 9 shows, the average EMU border estimate drops from $42.19 * 10^{-3}$ to $23.56 * 10^{-3}$, the implied 'real' width of the borders is 3,258 miles. These results confirm that - despite the drastic reduction in border estimates - there are still large and 'real' segmentations across European goods markets. 


\subsection{Volatility Measure 3}

In section 2, we justified our basic measure for integration by pointing out that it has some potential to take account of trend behavior in real exchange rates caused by nontradeable good components that are present in our index data. In this subsection we will propose an alternative way of measuring volatility of relative prices. To motivate our approach, assume that the price index of a country, $P$, can be written as the geometric mean of tradeable goods prices, $P_{T}$, and nontradeable goods prices, $P_{N}$, i.e.,

$$
P=P_{T}^{\alpha} * P_{N}^{1-\alpha},
$$

where $\alpha$ represents the tradeable goods weight in the total basket of goods. Denoting $\log$ values of a variable with small letters and assuming that the weight $\alpha$ is the same across regions/countries, the real exchange rate, $q_{i j}$, between region/country $i$ and $j$ can then be written as

$$
q_{i j}=s_{i j}+p_{T, j}-p_{T, i}+(1-\alpha)\left[\left(p_{T, i}-p_{N, i}\right)-\left(p_{T, j}-p_{N, j}\right)\right],
$$

where $s_{i j}$ denotes the nominal exchange rates between the two regions/countries. Following Canzoneri et al. (1999), the relative price of nontradeable in the presence of Balassa-Samuelson effects is given by

$$
\left(p_{T}-p_{N}\right)=\ln \left(A_{T}\right)-\ln \left(A_{N}\right)
$$

where $A_{x}$ (with $x=T, N$ ) denotes labor productivity in the traded (T) or nontraded goods sector $(\mathrm{N})$. Substituting this expression into equation (6) and simplifying notation gives us the following expression for the real exchange rate

$$
q_{i j}=v_{N}+u_{T}
$$

where $u_{T}$ represents the relative price of tradeables $\left(s_{i j}+p_{T, j}-p_{T, i}\right)$ and $v_{N}=$ $(1-\alpha)\left[\left(\ln \left(A_{T, i}\right)-\ln \left(A_{N, i}\right)\right)-\left(\ln \left(A_{T, j}\right)-\ln \left(A_{N, j}\right)\right)\right]$ represents relative productivity differentials in productivity growth between region $i$ and region $j$. When $\mathrm{PPP} /$ the LOOP holds, we expect $u_{T}$ to be zero or at least to be stationary. The time series behavior of $v_{N}$ depends on relative productivity developments between the considered regions. When there is a trend in relative productivity growth between region $i$ and region $j$ then $v_{N}$ will not be stationary.

To measure the integration of goods markets we are particularly interested in the first component $\left(u_{T}\right)$. When $u_{T}$ is close to zero (or reverts quickly to it after a deviation), then arbitrage forces are effective and markets are relatively integrated. In the following we make use of a very popular method to decompose our relative price series 
into a trend $\left(v_{N}\right)$ and a cyclical $\left(u_{T}\right)$ component. We will use the Hodrick-Prescott filter (with $\lambda=1600$ ) to retrieve the cyclical component of our relative prices. Results for measure 3 are presented in tables 12 and 13 . The upper panel of table 12 reports findings for specifications 1 to 4 for total index data. Estimates for the border coefficient, nominal exchange rate volatility and the intra-continental/EMU dummies have the same characteristics as those for the basic specification. There is one important difference, however: The distance coefficient becomes negative for specification 4 . The negative sign immediately vanishes when we consider individual border estimates for which results are reported in the lower panel of table 12. Results are very similar to those of the basic specifications. They confirm the strong reduction in EMU border estimates after January 1999 that is not accompanied by a comparable reduction in non-EMU border estimates. Distances are positively related to dispersion (even though the coefficient is partly not significant).

For the subcategories we find analogous results as for the basic measure. Results are presented in table 13. As the third panel of table 9 average border estimates for EMU-pairs drop significantly from subperiod 1 to 2 (from $11.95 * 10^{-3}$ to $5.02 * 10^{-3}$ ) whereas average NAFTA values also fall (but to a lesser extent) and EMU-NAFTA values increase. The implied real width of EMU borders is 552 miles again confirming that there are still considerable real frictions across European markets. 15

\section{Do Observed Differences Remain Valid in the Long Run?}

The last sections focussed on short- to medium-run movements in relative prices. As we saw, relative international prices are dominated by nominal exchange rate movements in the short and medium run. In the long-run, nominal prices adjust to their equilibrium values. As a consequence, observed differences in integration across markets should vanish at such a time horizon if they were caused mainly by nominal factors. In this section, we will therefore take a long-run perspective to examine into the question whether the considerable differences in market integration between intra-continental and inter-continental markets reported above are solely 'nominal' or also have real causes. To do so, we will rely on unit root analysis and will examine

\footnotetext{
${ }^{15}$ In tables $\mathrm{D}$ and $\mathrm{E}$ we report results when instead of the log of distance a quadratic distance specification (distance and distance squared) is used to approximate transportation costs. When transaction costs are convex we would expect the coefficient on distance to be positive and the coefficient on distance squared to be negative. The entries in table $\mathrm{D}$ basically confirm this intuition. However, as in the case of volatility measure 3, for specification 4, we find a 'perverse' result in the sense that higher distances are related with higher integration. This result vanishes immediately when individual border effects are estimated. Apart from that, results confirm our findings for the basic measure. EMU border effects reduce considerably (by around 90\%) from subperiod 2 to 3 whereas the other border coefficients show no tendency to reduce.
} 
convergence speeds of relative prices. The new aspect of our work is that we use - in addition to the international dimension - the regional dimension of our data. This allows us, in analogy to the procedure above, to compare intra-national and international goods market integration. We will start by reporting results obtained for single-equation augmented Dickey-Fuller (ADF) tests. Then we will panel our data and will perform both Levin-Lin and Im-Pesaran-Shin panel unit root tests.

\subsection{Single Equation Unit Root Tests}

In the first step of our long-run analysis, we will examine the main characteristics of the coefficients of mean reversion that we obtain from single-equation ADF tests of the form

$$
\Delta q_{i j, t}=\alpha_{i j}+\rho_{i j} * q_{i j, t-1}+\sum_{k=1}^{6} \phi_{i j, k} \Delta q_{i j, t-k}+\epsilon_{i j, t},
$$

where $q_{i j, t}$ denotes the relative price between two regions in period $t$. As data for subcategories are only available for 6.5 years, we do not include these data in our analysis. Additionally, as the time period for which we have observations available is relatively short (11.5 years) and as it is well documented that single-equation unit root tests lack power given such a short sample period we do not make an attempt to use results for our single-equation tests as evidence in favor of or against mean reversion. However, we are interested in an analysis of major characteristics of the obtained estimates for $\rho_{i j}$. A first overview of the properties of the estimated adjustment coefficients can be obtained from table 14. The upper panel ('Unadjusted Coefficients') of this table reports summary statistics for the unadjusted values of $\rho_{i j}$. As OLS estimates of the adjustment coefficients are biased downward in small samples the lower panel ('Adjusted Coefficients') contains summary statistics for adjusted values using the formula by Kendall (1954). To get a better idea of whether there are significant differences in the adjustment process of relative prices across country pairs we report descriptive results for various subsamples as, e.g., all intranational relative prices. We also report the implied half-lives of mean reversion.

Based on the results from the previous section we would expect to find the highest rate of convergence for intra-national relative prices followed by intra-continental and inter-continental relative prices. A look at table 14 shows, however, that this intuition is only partially confirmed. Whilst convergence is larger for intra-continental pairs (with an adjusted half-live of 0.8 years) than for inter-continental pairs (1.3 years), it is minimal for intra-national pairs: The half-life of deviation from its equilibrium value are more than 20 years. Whereas this result seems to be odd at first, there is a relatively straightforward explanation for it. When intra-national markets are - as suggested by the results from the previous sections - relatively well 
integrated, then real exchange probably will very likely move within the band of inactivity described in equation (4) most of the band. However, within this band, real exchange rates behave as random walks and thus show no indications of mean reversion. Thus, results for intra-national relative prices in table 14 are consistent with our findings from the previous section that these prices exhibit relatively small volatility. Overall, our results are in line with other findings in the literature. The fact of relative slow convergence in intra-national real exchange rates is confirmed by Cecchetti et al. (2002) who find evidence of very persistent real exchange rates across U.S. cities. Evidence of relatively large convergence in relative prices across EMU countries is presented in Goldberg and Verboven (2001).

In analogy to our procedure in the previous sections we now turn to an analysis of potential determinants of the degree of mean reversion. The results are presented in table 15. The dependent variable in all five specifications ('Spec. 1' to 'Spec. 5') are the estimated coefficients of adjustment, $\hat{\rho}_{i j}$. As explanatory variables we have chosen the same variables that we used to explain relative price dispersion. In specification 1, only (the log of) distance is included. We would expect the coefficient on distance to be positive as relative prices from more distant regions should converge more slowly than the corresponding prices from nearer regions. Contrary to our intuition, the estimated coefficient is negative. An explanation for this counter-intuitive result is found when we include a border dummy in addition to distance in the regression analysis ('Spec. 2'). The distance coefficient becomes positive (and stays significant). Unlike in the case of relative price dispersion, the border dummy has a highly significant negative impact on the estimated adjustment coefficient. The reason for this result was given above. As intra-national relative prices are close to equilibrium and thus exhibit random walk behavior, international real exchange are very likely driven outside the band of inactivity by large shocks most of the time and show stronger mean reverting behavior therefore. When nominal exchange rate volatility is included the basic results are not changed. Distance contributes negatively to mean reversion (although the coefficient is no longer significant at a $5 \%$ significance level) and a border between regions increases mean reversion. The coefficient on nominal exchange rate volatility turns out to be significantly positive even though nominal exchange rate volatility does not have the same explanatory power as in the cases of the previous sections (which one can see, e.g., from the only slight increase in $R_{a d j}^{2}$ ). Given that we are taking a long-run perspective, nominal exchange rate volatility should not play a significant role in the adjustment process. However, it is easily conceivable that the same real factors that imply a relative volatile nominal exchange rate also hinder adjustment. Thus, the negative impact of nominal exchange rate volatility on relative price adjustment is simply the outcome of a correlation caused by underlying real factors. When a dummy for 
EMU countries and NAFTA is included we find that intra-EMU real exchange rates have significantly higher rates of mean reversion than those between the U.S.A. and Canada. As results for single-equation ADF tests might lack precision due to the short period of available data we now turn to panel data results.

\subsection{Levin-Lin Panel Unit Root Tests}

Panel data techniques allow us to pool the experience of many bilateral real exchange rates and thus to increase the precision of our estimates. When constructing relative prices we choose one region/city for each country as base region/city. In most cases (besides the U.S.A. where we choose New York) we choose the capital city (or the region in which the capital city is located) as the base region/city. This gives us a total of 462 individual real exchange rates for which we have 11.5 years of data. 16 To examine the nature of mean reversion in panel data several procedures have been suggested in the last ten years. By far the most popular has been the Levin-Lin panel unit root test 17 that we also employ in this paper. At the center of this test is the equation 18

$$
\Delta \tilde{q}_{i, t}=\alpha_{i}+\rho \tilde{q}_{i, t-1}+\sum_{j=1}^{k_{i}} \phi_{i, j} \Delta \tilde{q}_{i, t-j}+\epsilon_{i, t}
$$

where $q_{i, t}$ denotes the real exchange rate between two regions in period $t$ and a tilde above a variable denotes its period's $t$ deviation from the cross-sectional mean, i.e., $\tilde{q}_{i, t}=q_{i, t}-\frac{1}{N} \sum_{j=1}^{N} q_{j, t}$. In this specification, $\alpha_{i}$ represents an individual-specific effect, $\theta_{t}$ represents a common-time effect and $\epsilon_{i, t}$ is a (possibly serially correlated) stationary idiosyncratic shock. Lagged values of $\Delta \tilde{q}_{i, t}$ are included to control for potential serial correlations in the error term $\epsilon_{i, t}$. While we equalize the $\rho$ 's across individuals we allow different degrees of serial correlation $k_{i}$ (with $i=1, \ldots, N$ ) across them. The number of lagged differences for each region is determined according to the general-to-specific method proposed by Hall (1994) and recommended by Campbell and Perron (1991). The Levin-Lin test procedure imposes (both for the null hypothesis of non-stationarity and for the alternative hypothesis of stationarity) the homogeneity restriction that all $\beta$ s are equal across individual regions. Thus,

\footnotetext{
${ }^{16}$ As we noticed in section 2, for some countries data are only available for around 10.5 years.

${ }^{17}$ See Levin and Lin (1992), Levin and Lin (1993) and Levin et al. (2002) for reference.

${ }^{18}$ Note that there is a switch in notation. This is supposed to indicate that the sample of relative prices underlying the panel unit root analysis is not identical to the sample used in previous sections due to our choice of a base city/region for each country. See the appendix for a more detailed description of our estimation procedure.
} 
the null hypothesis can be formulated as:

$$
H_{0}: \rho_{1}=\rho_{2}=\cdots=\rho_{N}=\rho=0
$$

and the alternative hypothesis (that all series are stationary) is given by:

$$
H_{1}: \rho_{1}=\rho_{2}=\cdots=\rho_{N}=\rho<0
$$

Levin and Lin (1993) provide asymptotically valid critical values for the studentized coefficient of $\rho$. These values might, however, be of minor usefulness in our relatively small sample. Thus, we obtain critical values for the estimated adjustment coefficient from a bootstrap procedure.19 We are using a nonparametric bootstrap based on the actually observed time series of error terms. To build up the bootstrap distribution of the adjustment coefficient $\rho$ under the null hypothesis we resample observed error vectors $\hat{e}_{j, t}$ and build up artificial real exchange rate series using the data generating process as estimated under the null hypothesis. The obtained estimate of $\rho$ is stored and the full process is repeated 5,000 times. Critical values are given by the $5 \%$ critical values of this distribution.

Results are presented in table 16. In addition to the estimated coefficients of adjustment $\rho$, we report adjusted coefficients (using the formula by Nickell (1981)), computed t-statistics, derived half-lives and the p-values that we obtained from the bootstrap procedure. The rows contain results for different subgroups of our overall sample. This allows us to get some idea of whether the adjustment process is different when, for example, intra-continental or inter-continental relative prices are considered. Our results on the border effects from the previous section suggest such a link. On the other hand, if differences were mainly caused by nominal exchange rate volatility in conjunction with rigid prices, then we would expect the differences between country groups to be less pronounced than documented in the last section. The results of table 16 show that there are significant differences in integration across intra-continental and inter-continental markets even in the long-run. When all relative prices are included in the analysis, we easily reject the null hypothesis of a unit root in relative prices and obtain an adjusted half-live of mean reversion of 1.9 years. When splitting the overall sample into intra-national and international relative prices, we find strong indications of mean reversion for all international relative prices (with an adjusted half-live of 1.8 years) and no mean reversion for intra-national relative prices. This result is interesting for two reasons: First, it demonstrates an important - and well documented - pitfall of the applied panel methods, namely that the rejection of the null hypothesis for a considered sample does not mean that all series of the sample are actually stationary. Secondly, the

\footnotetext{
${ }^{19}$ See the appendix for a more detailed description.
} 
results show that there are significant differences in the behavior of intra-national and international relative prices. Contrary to our intuition and the results obtained in the previous sections, intra-national markets seem to be less integrated in the long-run than international markets. As we explained in the last subsection where we examined single equation ADF tests, we think that this result shows that intranational relative prices are within a band of inactivity (caused by transportation costs) most of the time. Insofar, the long-run analysis confirms findings from the previous section that showed that intra-national markets are better integrated than international markets. When we split international relative prices further into intracontinental and intercontinental relative prices, we find that the rejection of a unit root for international relative prices is mainly caused by intra-continental series (with an adjusted half-live of only 1.2 years). For inter-continental relative prices we cannot reject the null hypothesis of a unit root. This latter result confirms with our findings from the last section and shows that the differences in relative price behavior between intra-continental and inter-continental relative prices are not only a short and medium run phenomenon but also apply to the long-run. To see whether there are differences in relative price behavior within the groups of intra-continental and inter-continental relative prices, we split both groups further. Intra-continental relative prices are split into EMU and NAFTA series. The results from this exercise show that there is strong mean reversion across EMU countries (with a half-live of 8 month), whereas there is only weak evidence in favor of mean reversion between the U.S.A. and Canada. For inter-continental relative prices we find that series are relatively homogenous in the sense that we reject the null hypothesis of a unit root in all three cases (EMU-NAFTA, EMU-JA, NAFTA-JA) and obtain relatively similar half-lives. Overall, the results from the Levin-Lin panel unit root tests suggest that the differences in estimated border effects obtained in the previous section are not only a short-run phenomenon (caused by highly volatile nominal exchange rates) but remain valid when longer horizons are considered.

\subsection{Im-Pesaran-Shin Panel Unit Root Tests}

One of the major drawbacks of the Levin-Lin test is that it assumes that all adjustment coefficients are equal under the alternative hypothesis. This (very strong) assumption is given up in the panel unit root test suggested by Im et al. (2002). Their test procedure combines the studentized coefficients obtained from the individual ADF tests to a joint test of convergence. To perform the Im-Pesaran-Shin (IPS) test we start by individually estimating all real exchange rates, i.e., by indi- 
vidually estimating the equation

$$
\Delta \tilde{q}_{i, t}=\alpha_{i}+\rho_{i} \tilde{q}_{i, t-1}+\sum_{j=1}^{k_{i}} \phi_{i, j} \Delta \tilde{q}_{i, t-j}+\epsilon_{i, t},
$$

where the same notation applies as for the Levin-Lin test. Let $\tau_{i}$ denote the studentized coefficient from real exchange rate $i$ (where $\tau_{i}$ is computed as the ratio of $\rho_{i}$ divided by its estimated standard error), then the IPS test statistics is obtained as the mean over all $\tau_{i}$, i.e., is given by

$$
\tau_{I P S}=\frac{1}{N} \sum_{i=1}^{N} \tau_{i},
$$

where $N$ denotes the number of real exchange rates included in the respective panel. Again, critical values are obtained using bootstrap procedures. We resample estimated error term vectors to build up artificial panels of real exchange rates under the null hypothesis. Then, we compute the IPS test statistics and repeat this procedures 5,000 times to build up a bootstrap distribution for $\tau_{I P S}$. The reported critical values are based on this bootstrap distribution.

Results for both the estimated coefficients of adjustment and critical values are presented in table 17. As the IPS does not directly provide a single estimate for the adjustment coefficient $\rho$, we report mean values from the estimated individual values. The adjusted coefficient is obtained using the formula by Kendall (1954). The results for the IPS tests confirm the findings from the Levin-Lin tests. We find strong mean reversion for EMU relative prices (with half-lives of 1.1 years) and weak mean reversion for U.S.-Canadian relative prices. No mean reversion is found for intra-national relative prices and for inter-continental relative prices. Overall, the IPS tests confirm our conclusions concerning the relative integration of international goods markets. Table 17 shows that there are differences in convergence speed (and thus integration) across country groups and that these differences not only apply at medium but also long-run horizons.

\section{Summary and Conclusions}

It has been the objective of this paper to analyze patterns of intra-national and international relative price behavior to gain insights into the degree of international goods market integration. To do so we used an approach that has gained popularity in the last years. This approach uses a regional perspective. This enables us not only to compare intra-national with international relative price behavior but also allows us to obtain more precise estimates as the number of available observations 
is drastically increased. An important question that we addressed in this paper concerned the relative importance of real and nominal determinants of the so-called border effect in relative price dispersion. Additionally, we tried to integrate the (more short-run oriented) border literature with the (more long-run oriented) literature on real exchange rate convergence to learn how estimates from the former are to be evaluated when a long-run perspective is taken. To answer these questions we constructed a very broad sample of regional data that includes nine major industrialized countries and consists of a total of 110 regions.

In the first part of our analysis, we examine short to medium-run relative price dispersion. We find that transaction costs (approximated by distance) play a significant role for the disintegration of markets. However, borders seems to have a much more important effect. Additionally, there seems to be some sort of 'ocean' effect as inter-continental borders seem to be of a considerably higher importance than intra-continental borders. All these results are in line with our intuition as countries that are part of the same continent are likely to have more interactions than countries that are separated by an ocean. Potential reasons for such an 'ocean' effect can easily be derived from economic theory. So, it is surely plausible that pricing-to-market is more pronounced for markets that are separated by an ocean as these markets are likely to be more segmented. Additionally, labor markets are probably more integrated on the same continent. Moreover, distribution and marketing channels are more homogeneous across countries that are part of the same continent. While all these factors may play a role for our results (which we cannot answer due to a lack of appropriate data, unfortunately) nominal exchanger rate volatility in conjunction with rigid prices plays the most prominent role for the observed results. When nominal exchange rate volatility is included in our regression, its coefficient is highly significant and close to 1 . Additionally, the importance of other considered factors drops drastically. Thanks to the broadness of our data sample, we can show that including a measure for nominal exchange rate volatility (to control for the 'nominal' part of the border) might lead to biases in the estimate of the border dummy. Thus, the remaining border effect (after nominal exchange rate volatility is controlled for) might understate the 'real' part of the border effect. As it is this part of the border effect that matters for potential welfare losses from disintegration, it is of large importance for policy-makers to get good estimates of it.

Our analysis is able to provide such a measure. As nominal exchange rate volatility across EMU countries was (exogenously) eliminated in January 1999, any remaining border effect is a 'real' border effect. Our estimate for the 'width' of EMU borders suggest a value of around 5,000 miles which is - despite the drastic drop in the overall value of EMU border effects (around 90\%) - still an indication of considerable 
disintegration across EMU markets. Another noteworthy result is that a comparable drop in border estimates (relative to EMU borders) does not occur for non-EMU borders. This is strong evidence for the hypothesis that the drop in relative price dispersion has not been caused by real factors (such as a decline in barriers to trade) but exclusively by nominal factors. Our sensitivity analysis basically confirms the results from the basic specification.

Our basic findings concerning the heterogeneity of integration across intra-continental and inter-continental goods markets are confirmed when we take a long-run perspective. If nominal factors were the main determinants of the observed differences in border effects across country groups these differences should diminish when a longrun perspective is taken (when prices adjust). Our results for estimated coefficients of adjustment for real exchange rates only weakly support this view. We demonstrate that convergence speed positively depends on distance and nominal exchange rate volatility that plays a less prominent role than for short-run real exchange rate dispersion, however. Comparing country groups, we find significant differences in adjustment speeds for intra-continental and inter-continental relative prices. In line with our medium-run analysis, we can confirm that European markets seem to be integrated best, whereas inter-continental markets are heavily segmented. Thus, we confirm previous findings that international goods markets are not perfectly integrated and that 'real' border effects play an important role even if a long-run perspective is taken.

To sum it up, our paper provides strong evidence in favor of disintegration effects across international goods markets. Additionally, our paper is amongst the first studies that directly measures the 'real' width of the border. As only this part of the border effects seems to matter for welfare, our results are important for policymakers. Interestingly, to our knowledge, no systematic effort has been made to assess the welfare losses from real exchange rate dispersion of the kind that we investigated. We think that this is a deficiency in the existing literature as this aspect is of crucial importance for the question of whether observed disintegration is harmful (and thus something to worry about) or not (and thus to be neglected). In our opinion future research in this field has to clarify this question. 


\section{Tables}

Table 1: Countries and Regions/Cities Included in our Study

$$
\text { U.S.A (9 metropolitan areas) }
$$

Boston, Chicago, Cleveland, Detroit, Houston, Los Angeles, New York, Philadelphia, San Francisco

Source: Bureau of Labor Statistics; Coverage: 1991.01 - 2002.12

$$
\text { Canada (12 provinces) }
$$

Prince Edwards Islands, Alberta, New Brunswick, Nova Scotia, Quebec, Saskatchewan, New Foundland, Ontario, British Colombia, Yukon, Manitoba, Yellowknife

Source: Statistics Canada; Coverage 1991.01 - 2002.12

$$
\text { Japan (20 prefectures) }
$$

Chiba, Fukuoka, Fukushima, Gifu, Hiroshima, Kanazawa, Kobe, Kyoto, Maebashi, Mito, Nagano, Nagoya, Niigata, Osaka, Sapporo, Sendai, Shizuoka, Ku-area of Tokyo, Urawa, Yokohama

Source: Statistics Bureau and Statistics Center, Ministry of Public Management, Home Affairs, Post and Telecommunications; Coverage 1991.01 - 2001.04

$$
\text { Germany (9 regions) }
$$

Berlin, Sachsen, Nordrhein-Westfalen, Thueringen, Niedersachsen, Bayern, Saarland, Baden-Wuerttemberg, Hessen

Source: Statistical Offices of the German 'Laender'; Coverage: 1991.01 - 2002.12

$$
\text { Austria (10 cities) }
$$

Eisenstadt, Graz, Innsbruck, Klagenfurt, Linz, Salzburg, St. Poelten, Villach, Wels, Wien

Source: Statistics Austria; Coverage: 1991.01 - 2002.12

$$
\text { Finland (5 regions) }
$$

Uusimaa, Southern Finland, Eastern Finland, Mid-Finland, Northern Finland

Source: Statistics Finland; Coverage: 1995.01 - 2002.12

$$
\text { Italy (20 cities) }
$$

Ancona, Aosta, Bari, Bologna, Cagliari, Campobas, Firenze, Genova, L'Aquila, Milano, Napoli, Palermo, Perugia, Potenza, Reggio Calabria, Roma, Torino, Trento, Trieste, Venezia

Source: Istituto Nazionale di Statisticia (ISTAT); Coverage: 1991.01 - 2002.12

$$
\text { Spain (18 provinces) }
$$

Castilla la Mancha, Extremadura, Cataluna, Ceuta et Melilla, Galicia, Canarias, La Rioja, Madrid, Murcia, Asturias, Baleares, Navarra, Pais Vasco, Cantabria, Aragon, Andalucia, Valencia, Castilla Leon

Source: Instituto Nacional de Estadistica (INE); Coverage: 1991.01 - 2002.12

$$
\text { Portugal (7 regions) }
$$

Centro, Alentejo, Algarve, Madeira, Lisboa e vale tejo (LVT), Acores, Norte

Source: Instituto Nacional de Estatistica (INE); Coverage: 1991.01 - 2002.12 
Table 2: Categories Used in Our Study

\begin{tabular}{|c|c|c|c|c|}
\hline Category & U.S.A & Canada & Japan & EMU \\
\hline allit & Total Index & Total Index & Total Index & Total Index \\
\hline food & $\begin{array}{l}\text { Food at home } \\
\text { (includes non- } \\
\text { alcoholic bev- } \\
\text { erages) }\end{array}$ & $\begin{array}{lr}\text { Food } & \text { pur- } \\
\text { chased } & \text { from } \\
\text { stores } & \text { (in- } \\
\text { cludes } & \text { non- } \\
\text { alcoholic } & \\
\text { beverages) }\end{array}$ & - & $\begin{array}{l}\text { Food and non- } \\
\text { alcoholic bev- } \\
\text { erages }\end{array}$ \\
\hline alco & - & $\begin{array}{l}\text { Alcoholic bev- } \\
\text { erages and to- } \\
\text { bacco }\end{array}$ & - & $\begin{array}{l}\text { Alcoholic bev- } \\
\text { erages and to- } \\
\text { bacco products }\end{array}$ \\
\hline clot & $\begin{array}{l}\text { Clothing and } \\
\text { footwear }\end{array}$ & Apparel & - & $\begin{array}{l}\text { Clothing and } \\
\text { footwear }\end{array}$ \\
\hline hous & $\begin{array}{l}\text { Shelter }+\mathrm{Fu}- \\
\text { els and utilities }\end{array}$ & Shelter & - & $\begin{array}{l}\text { Housing, wa- } \\
\text { ter, electricity, } \\
\text { gas and other } \\
\text { fuels }\end{array}$ \\
\hline furn & $\begin{array}{l}\text { Household } \\
\text { furnishings } \\
\text { and operations }\end{array}$ & $\begin{array}{l}\text { Household } \\
\text { operations and } \\
\text { furnishings } . / \cdot \\
\text { Communica- } \\
\text { tions }\end{array}$ & - & $\begin{array}{l}\text { Furnishings, } \\
\text { household } \\
\text { equipment } \\
\text { and routine } \\
\text { maintainence } \\
\text { of the house }\end{array}$ \\
\hline heal & Medical care & Health care & - & Health \\
\hline $\operatorname{tran}$ & Transportation & Transportation & - & Transport \\
\hline
\end{tabular}

Notes:

1) EMU countries are: Germany, Austria, Finland, Italy, Spain and Portugal. For Austria, only total index data are available.

2) Bold-face categories are considered to be 'tradeable' goods categories.

3) The symbols ' +' and './.' indicate that the respective category for that country is constructed using two other categories by either combining the two categories $(+)$ or subtracting one from the other (./.). Weights to construct composite categories (such as furn for Canada) are obtained from the respective statistical offices. For all regions of one country, national weights are used. 
Table 3: Some Descriptive Statistics

\begin{tabular}{lllllll}
\hline \hline Category & \multirow{2}{*}{ Obs. } & All & Intra-N. & Intern. & Intra-C. & Inter-C. \\
\hline allit & \multirow{2}{*}{5987} & 32.83 & 3.78 & 36.92 & 16.25 & 49.63 \\
& & $(20.31)$ & $(1.58)$ & $(18.29)$ & $(5.68)$ & $(9.81)$ \\
food & \multirow{2}{*}{3152} & 24.26 & 8.00 & 27.35 & 15.58 & 40.75 \\
& & $(13.84)$ & $(3.46)$ & $(12.88)$ & $(3.31)$ & $(2.19)$ \\
alco & \multirow{2}{*}{3073} & 25.96 & 7.44 & 29.52 & 18.49 & 41.83 \\
& & $(14.06)$ & $(7.23)$ & $(12.12)$ & $(3.82)$ & $(2.7)$ \\
clot & \multirow{2}{*}{3152} & 44.21 & 13.67 & 50.02 & 39.36 & 62.15 \\
& & $(24.09)$ & $(13.67)$ & $(21.07)$ & $(19.59)$ & $(15.36)$ \\
hous & \multirow{2}{*}{3152} & 31.61 & 15.71 & 34.64 & 16.79 & 54.94 \\
& & $(31.2)$ & $(27.43)$ & $(30.96)$ & $(14.76)$ & $(32.04)$ \\
furn & \multirow{2}{*}{3152} & 22.51 & 6.36 & 25.58 & 12.05 & 40.98 \\
& & $(15.38)$ & $(4.16)$ & $(14.81)$ & $(3.87)$ & $(2.43)$ \\
heal & \multirow{2}{*}{3152} & 24.27 & 8.02 & 27.36 & 16.36 & 39.88 \\
& & $(13.79)$ & $(3.64)$ & $(12.81)$ & $(6.63)$ & $(2.52)$ \\
tran & \multirow{2}{*}{3152} & 23.26 & 7.08 & 26.34 & 14.26 & 40.08 \\
& & $(13.79)$ & $(4.75)$ & $(13.26)$ & $(3.59)$ & $(2.52)$ \\
\hline all & & 28.80 & 9.87 & 32.41 & 19.77 & 46.76 \\
tradeable & & 28.04 & 8.87 & 33.12 & 21.37 & 46.43 \\
non-trad. & & 27.94 & 10.27 & 29.45 & 15.80 & 44.97 \\
\hline avg.dist. & & 5191 & 664 & 5836 & 1583 & 8453 \\
\hline \hline
\end{tabular}

\section{Notes:}

1) Table 3 reports means and standard deviations of our measure of relative price volatility. The volatility of the real exchange rate between region $i$ and region $j$, denoted as $V\left(q_{i j}\right)$, is computed as the standard deviation of two-month relative price changes between the two regions, i.e.,

$$
V\left(q_{i j}\right)=\sqrt{\operatorname{var}\left(\Delta q_{i j, t}\right)}
$$

where $\Delta q_{i j, t}$ denotes the two-month change in regions' $i$ and $j$ relative price and $\operatorname{var}($.$) denotes the$ empirical variance of $\Delta q_{i j, t}$.

2) Bold-face categories are considered to be 'tradeable' goods categories.

3) Standard deviations are computed over all relative price measures included in the respective sample.

4) All numbers are multiplied by 1,000. The sample period is 1995.01-2002.12. 
Table 4: All Items, 'Aggregate' Border Estimates, Total Period

\begin{tabular}{lllll}
\hline \hline \multicolumn{5}{c}{ Estimated Equation: $V\left(q_{i j}\right)=\sum_{k=1}^{l} \beta_{k} * x_{i j, k}+$ regdum $+\epsilon_{i j}$} \\
\hline Expl. Var. & Spec. 1 & Spec. 2 & Spec. 3 & Spec. 4 \\
\hline (ln)dist & 13.63 & 10.49 & 0.35 & 0.22 \\
& $(106.41)$ & $(68.19)$ & $(10.98)$ & $(5.85)$ \\
border & & 13.84 & -1.82 & 1.08 \\
& & $(25.97)$ & $(-12.39)$ & $(2.18)$ \\
n.e.r.vol. & & & 0.94 & 0.90 \\
& & & $(268.31)$ & $(104.17)$ \\
intra-cont. & & & & -1.81 \\
& & & & $(-7.39)$ \\
\hline$R_{\text {adj }}^{2}$ & 0.860 & 0.890 & 0.996 & 0.996 \\
s.e.r. & 0.0069 & 0.0061 & 0.0012 & 0.0012 \\
\hline \hline
\end{tabular}

Notes:

1) Table 4 reports results from estimating equation (3) in section 3 of the main text. The term $V\left(q_{i j}\right)$ denotes our measure of relative price volatility computed as described in the notes of table 3. The term $x_{i j, k}$ represents the explanatory variables that are listed on the first column and that are described in more detail in section 3. The estimated coefficient $\beta_{k}$ denote the impact of variable $x_{i j, k}$ on relative price volatility. 'regdumm' represents regional dummy variables. $e_{i j}$ is assumed to be a mean-zero innovation term. All coefficients apart from those on nominal exchange rate volatility (n.e.r.vol.) are multiplied by 1,000.

2) In brackets, t-statistics are reported. In computing these statistics, White's heteroscedasticconsistent standard errors were used.

3) $R_{a d j}^{2}$ denotes the adjusted coefficient of determination, the term s.e.r. denotes the standard error of regression. 
Table 5: All Items, Regression Results for Individual Border Estimates, Total Period, Summary Results

\begin{tabular}{llllllllll}
\hline \hline \multicolumn{1}{c}{ Estimated Equation: $V\left(q_{i j}\right)=\sum_{k=1}^{l} \beta_{k} * x_{i j, k}+$ regdum $+\epsilon_{i j}$} \\
\hline Period & $($ ln)dist & emu & nafta & emu-nafta & emu-ja & nafta-ja & $R_{\text {adj }}^{2}$ & s.e.r. \\
\hline allit & 0.17 & 17.96 & 12.22 & 38.22 & 50.97 & 45.45 & 0.998 & 0.0009 \\
(w.o.finl.) & $(3.58)$ & $(10.84)$ & $(0.0)$ & $(2.04)$ & $(4.46)$ & $(0.38)$ & & \\
allit & 0.10 & 11.10 & 12.30 & 34.10 & 53.02 & 52.23 & 0.998 & 0.0009 \\
(incl.finl.) & $(2.25)$ & $(6.04)$ & $(0.0)$ & $(1.22)$ & $(3.63)$ & $(1.48)$ & & \\
\hline \hline
\end{tabular}

\section{Notes:}

1) Table 5 reports means of estimated border effects between countries that are classified to belong to one of five different country groups. The country group 'emu' refers to all within European country groups (germ-aust, germ-finl, germ-ital, germ-spai, germ-port, aust-finl, aust-ital, aust-spai, aust-port, finl-ital, finl-spai, finl-port, ital-spai, ital-port, spai-port), 'nafta' refers to the U.S.-Canadian border, 'emu-nafta' refers to European-North American borders (germ-usa, germ-cana, aust-usa, aust-cana, finl-usa, finl-cana, ital-usa, ital-cana, spai-usa, spai-cana, port-usa, port-cana), 'emu-ja' refers to European-Japanese borders (germ-ja, aust-ja, finl-ja, ital-ja, spai-ja, port-ja) and the term 'nafta-ja' refers to North American-Japanese borders (usa-ja, cana-ja). Numbers in brackets denote the t-statistics (for (ln)dist) or the standard deviation of numbers in the respective group (for border estimates). Detailed results for the shorter sample (incl. Finland) can be found in table $\mathrm{A}$ of appendix $\mathrm{A}$.

2) Results are obtained from estimating equation (3) in section 3 of the main text. The term $V\left(q_{i j}\right)$ denotes our measure of relative price volatility computed as described in the notes of table 3 . A description of the other variables is given in the notes of table 4. All coefficients are multiplied by 1,000 .

3) In brackets, t-statistics are reported. In computing these statistics, White's heteroscedasticconsistent standard errors were used.

4) $R_{a d j}^{2}$ denotes the adjusted coefficient of determination, the term s.e.r. denotes the standard error of regression. 
Table 6: Subcategories, Regression Results for Individual Border Estimates, Total Period, Summary Results

\begin{tabular}{lllllll}
\hline \hline \multicolumn{6}{c}{ Estimated Equation: $V\left(q_{i j}\right)=\sum_{k=1}^{l} \beta_{k} * x_{i j, k}+$ regdum $+\epsilon_{i j}$} \\
\hline Category & (ln)dist & emu & nafta & emu-nafta & $R_{a d j}^{2}$ & s.e.r. \\
\hline food & 0.64 & 6.93 & 8.53 & 28.45 & 0.993 & 0.0012 \\
& $(5.69)$ & $(1.79)$ & $(0.0)$ & $(2.62)$ & & \\
alco & 0.33 & 10.49 & 8.35 & 30.65 & 0.986 & 0.0016 \\
& $(1.92)$ & $(2.65)$ & $(0.0)$ & $(2.8)$ & & \\
clot & 1.25 & 27.17 & 12.43 & 37.74 & 0.967 & 0.0044 \\
& $(3.42)$ & $(10.58)$ & $(0.0)$ & $(6.39)$ & & \\
hous & 0.53 & 6.85 & 11.33 & 28.41 & 0.994 & 0.0025 \\
& $(1.81)$ & $(2.02)$ & $(0.0)$ & $(0.99)$ & & \\
furn & 0.46 & 5.99 & 7.91 & 30.04 & 0.996 & 0.0009 \\
& $(5.73)$ & $(1.74)$ & $(0.0)$ & $(2.62)$ & & \\
heal & 0.37 & 8.90 & 9.38 & 30.29 & 0.990 & 0.0014 \\
& $(3.84)$ & $(4.09)$ & $(0.0)$ & $(2.16)$ & & \\
tran & 0.84 & 7.08 & 8.37 & 28.00 & 0.993 & 0.0012 \\
& $(7.18)$ & $(1.58)$ & $(0.0)$ & $(1.62)$ & & \\
\hline all & 0.63 & 10.49 & 9.47 & 30.51 & & \\
\hline \hline
\end{tabular}

Notes:

1) Table 6 reports means of estimated border effects between countries that are classified to belong to one of three different country groups that are described in more detail in the footnotes of table 5. Numbers in brackets denote the t-statistics (for (ln)dist) or the standard deviation of estimated values in the respective group (for border estimates). The detailed results can be found in table $\mathrm{A}$ of appendix A.

2) Results are obtained from estimating equation (3) in section 3 of the main text. The term $V\left(q_{i j}\right)$ denotes our measure of relative price volatility computed as described in the notes of table 3 . A description of the other variables is given in the notes of table 4 . All coefficients are multiplied by 1,000 .

3) In brackets, t-statistics are reported. In computing these statistics, White's heteroscedasticconsistent standard errors were used.

4) $R_{a d j}^{2}$ denotes the adjusted coefficient of determination, the term s.e.r. denotes the standard error of regression.

5) A more detailed description of the individual subcategories can be found in table 2 . 
Table 7: All Items, Regression Results for Individual Border Estimates, Subperiods, Summary Results

\begin{tabular}{llllllllll}
\hline \hline \multicolumn{8}{c}{ Estimated Equation: $V\left(q_{i j}\right)=\sum_{k=1}^{l} \beta_{k} * x_{i j, k}+$ regdum $+\epsilon_{i j}$} \\
\hline Period & (ln)dist emu & nafta & emu-nafta & emu-ja & nafta-ja & $R_{\text {adj }}^{2}$ & s.e.r. \\
\hline \multirow{2}{*}{$91.01-94.12$} & 0.19 & 20.85 & 11.36 & 46.70 & 43.50 & 30.38 & 0.995 & 0.0013 \\
& $(2.91)$ & $(8.26)$ & $(0.00)$ & $(4.82)$ & $(6.93)$ & $(3.65)$ & & \\
$95.01-98.12$ & 0.01 & 16.53 & 11.92 & 33.34 & 52.23 & 59.93 & 0.997 & 0.0011 \\
& $(0.10)$ & $(8.96)$ & $(0.00)$ & $(2.66)$ & $(5.52)$ & $(2.65)$ & & \\
$99.01-02.12$ & 0.21 & 2.20 & 12.41 & 35.00 & 55.01 & 39.83 & 0.998 & 0.0009 \\
& $(3.84)$ & $(0.88)$ & $(0.00)$ & $(0.71)$ & $(1.04)$ & $(1.12)$ & & \\
\hline \hline
\end{tabular}

\section{Notes:}

1) Table 7 reports means of estimated border effects between countries that are classified to belong to one of five different country groups that are described in more detail in the notes of table 5 . Results are obtained for three different subperiods of the total sample period (as indicated in the first column). Numbers in brackets denote the t-statistics (for (ln)dist) or the standard deviation of estimated values in the respective group (for border estimates). The detailed results for the second and third subperiod can be found in tables $\mathrm{B}$ and $\mathrm{C}$ of appendix $\mathrm{A}$.

2) For further notes, see table 5. 
Table 8: Subcategories, Regression Results for Individual Border Estimates, Subperiods, Summary Results

\begin{tabular}{|c|c|c|c|c|c|c|}
\hline \multicolumn{7}{|c|}{ Estimated Equation: $V\left(q_{i j}\right)=\sum_{k=1}^{l} \beta_{k} * x_{i j, k}+$ regdum $+\epsilon_{i j}$} \\
\hline Period & $(\ln )$ dist & $\mathrm{emu}$ & nafta & emu-nafta & $R_{a d j}^{2}$ & s.e.r. \\
\hline \multicolumn{7}{|l|}{ food } \\
\hline $95.01-98.12$ & $\begin{array}{l}0.66 \\
(5.16)\end{array}$ & $\begin{array}{l}10.27 \\
(2.12)\end{array}$ & $\begin{array}{l}8.09 \\
(0.0)\end{array}$ & $\begin{array}{l}27.52 \\
(3.5)\end{array}$ & 0.986 & 0.0015 \\
\hline $99.01-02.12$ & $\begin{array}{l}0.56 \\
(4.48)\end{array}$ & $\begin{array}{l}3.73 \\
(1.85)\end{array}$ & $\begin{array}{l}8.36 \\
(0.00)\end{array}$ & $\begin{array}{l}29.98 \\
(2.22)\end{array}$ & 0.991 & 0.0014 \\
\hline \multicolumn{7}{|l|}{ alco } \\
\hline $95.01-98.12$ & $\begin{array}{l}0.07 \\
(0.29)\end{array}$ & $\begin{array}{l}14.44 \\
(3.19)\end{array}$ & $\begin{array}{l}8.10 \\
(0.00)\end{array}$ & $\begin{array}{l}29.89 \\
(3.31)\end{array}$ & 0.965 & 0.0024 \\
\hline $99.01-02.12$ & $\begin{array}{l}0.72 \\
(5.70)\end{array}$ & $\begin{array}{l}5.70 \\
(2)\end{array}$ & $\begin{array}{l}8.46 \\
(0.00)\end{array}$ & $\begin{array}{l}31.34 \\
(2.2)\end{array}$ & 0.992 & 0.0015 \\
\hline \multicolumn{7}{|l|}{ clot } \\
\hline $95.01-98.12$ & $\begin{array}{l}0.94 \\
(2.92)\end{array}$ & $\begin{array}{l}21.72 \\
(9.7)\end{array}$ & $\begin{array}{l}6.73 \\
(0.00)\end{array}$ & $\begin{array}{l}33.49 \\
(5.51)\end{array}$ & 0.972 & 0.0035 \\
\hline $99.01-02.12$ & $\begin{array}{l}1.54 \\
(3.20)\end{array}$ & $\begin{array}{l}30.17 \\
(12.57)\end{array}$ & $\begin{array}{l}17.13 \\
(0.00)\end{array}$ & $\begin{array}{l}40.56 \\
(10.42)\end{array}$ & 0.957 & 0.0058 \\
\hline \multicolumn{7}{|l|}{ hous } \\
\hline $95.01-98.12$ & $\begin{array}{l}0.44 \\
(2.20)\end{array}$ & $\begin{array}{l}11.02 \\
(3.19)\end{array}$ & $\begin{array}{l}7.49 \\
(0.00)\end{array}$ & $\begin{array}{l}27.34 \\
(3)\end{array}$ & 0.977 & 0.0023 \\
\hline $99.01-02.12$ & $\begin{array}{l}0.66 \\
(1.52)\end{array}$ & $\begin{array}{l}1.91 \\
(0.83)\end{array}$ & $\begin{array}{l}14.43 \\
(0.00)\end{array}$ & $\begin{array}{l}29.55 \\
(1.01)\end{array}$ & 0.994 & 0.0034 \\
\hline \multicolumn{7}{|l|}{ furn } \\
\hline $95.01-98.12$ & $\begin{array}{l}0.69 \\
(5.73)\end{array}$ & $\begin{array}{l}9.60 \\
(2.76)\end{array}$ & $\begin{array}{l}6.29 \\
(0.00)\end{array}$ & $\begin{array}{l}27.77 \\
(4.22)\end{array}$ & 0.989 & 0.0014 \\
\hline $99.01-02.12$ & $\begin{array}{l}0.24 \\
(2.67)\end{array}$ & $\begin{array}{l}0.75 \\
(0.39)\end{array}$ & $\begin{array}{l}9.10 \\
(0.00)\end{array}$ & $\begin{array}{l}32.52 \\
(0.91)\end{array}$ & 0.996 & 0.0011 \\
\hline \multicolumn{7}{|l|}{ heal } \\
\hline $95.01-98.12$ & $\begin{array}{l}0.24 \\
(2.01)\end{array}$ & $\begin{array}{l}14.52 \\
(6.04)\end{array}$ & $\begin{array}{l}8.94 \\
(0.00)\end{array}$ & $\begin{array}{l}28.72 \\
(2.99)\end{array}$ & 0.981 & 0.0017 \\
\hline $99.01-02.12$ & $\begin{array}{l}0.43 \\
(4.30)\end{array}$ & $\begin{array}{l}1.70 \\
(1.37)\end{array}$ & $\begin{array}{l}9.62 \\
(0.00)\end{array}$ & $\begin{array}{l}31.79 \\
(1.69)\end{array}$ & 0.989 & 0.0017 \\
\hline \multicolumn{7}{|l|}{$\operatorname{tran}$} \\
\hline $95.01-98.12$ & $\begin{array}{l}0.44 \\
(4.62)\end{array}$ & $\begin{array}{l}9.78 \\
(2.35)\end{array}$ & $\begin{array}{l}7.98 \\
(0.0)\end{array}$ & $\begin{array}{l}27.98 \\
(2.66)\end{array}$ & 0.993 & 0.0011 \\
\hline $99.01-02.12$ & $\begin{array}{l}1.14 \\
(6.75)\end{array}$ & $\begin{array}{l}4.54 \\
(2.09)\end{array}$ & $\begin{array}{l}8.70 \\
(0.0)\end{array}$ & $\begin{array}{l}28.80 \\
(2.69)\end{array}$ & 0.988 & 0.0018 \\
\hline
\end{tabular}

\section{Notes:}

1) Table 8 reports means of estimated border effects between countries that are classified to belong to one of three different country groups that are described in more detail in the notes of table 5 . Results are obtained for two different subperiods of the total sample period (as indicated in the first column). Numbers in brackets denote the t-statistics (for (ln)dist) or the standard deviation of estimated values in the respective group (for border estimates). The detailed results can be found in tables $\mathrm{B}$ and $\mathrm{C}$ of appendix $\mathrm{A}$.

2) For further notes, see table 6 . 
Table 9: Subcategories, Estimated Average Distance and Border Coefficients for Volatility Measures 1 to 3, Subperiods

\begin{tabular}{lcccc}
\hline \hline Period & (ln)dist & emu & nafta & emu-nafta \\
\hline \multicolumn{5}{c}{ Volatility Measure 1 } \\
\hline $95.01-98.12$ & 0.49 & 13.05 & 7.66 & 28.96 \\
$99.01-02.12$ & 0.76 & 6.93 & 10.83 & 32.08 \\
\hline \multicolumn{5}{c}{ Volatility Measure 2 } \\
\hline \multicolumn{5}{c}{40.19} \\
$95.01-98.12$ & 1.63 & 26.35 & 97.61 \\
$99.01-02.12$ & 2.75 & 23.56 & 36.58 & 103.01 \\
\hline \multicolumn{5}{c}{ Volatility Measure 3 } \\
\hline $95.01-98.12$ & 0.50 & 11.95 & 15.23 & 38.08 \\
$99.01-02.12$ & 0.74 & 5.02 & 10.72 & 43.62 \\
\hline \hline
\end{tabular}

Notes:

1) Table 9 reports average estimated distance and border coefficients from tables 8 (volatility measure 1), 11 (volatility measure 2) and 13 (volatility measure 3).

2) Volatility measure 1 is computed as the standard deviation of two-month relative price changes between two regions. Volatility measure 2 is the spread between the $10 \%$ and the $90 \%$ percentile of the distribution of bi-monthly relative price changes. Volatility measure 3 is given by the standard deviation of the cyclical component of the HP-filtered relative price series.

3) For further notes, see tables 8,11 and 13 . 
Table 10: All Items, Aggregate and Individual Border Estimates, Volatility Measure 2

\begin{tabular}{|c|c|c|c|c|c|c|c|c|}
\hline \multicolumn{9}{|c|}{ Estimated Equation: $y=\sum_{k=1}^{l} \beta_{k} * x_{i j, k}+$ regdum $+\epsilon_{i j}$} \\
\hline \multicolumn{9}{|c|}{ Specifications 1 to 4} \\
\hline Spec & $(\ln )$ dist & border & n.e.r.vol. & intra-c. & $R_{a d j}^{2}$ & s.e.r. & & \\
\hline 1 & $\begin{array}{l}43.95 \\
(107.03)\end{array}$ & & & & 0.863 & 0.0220 & & \\
\hline 2 & $\begin{array}{l}35.05 \\
(68.06)\end{array}$ & $\begin{array}{l}39.26 \\
(23.33)\end{array}$ & & & 0.885 & 0.0201 & & \\
\hline 3 & $\begin{array}{l}2.61 \\
(17.25)\end{array}$ & $\begin{array}{l}-10.86 \\
(-25.4)\end{array}$ & $\begin{array}{l}3.02 \\
(241.83)\end{array}$ & & 0.990 & 0.0059 & & \\
\hline 4 & $\begin{array}{l}1.76 \\
(11.07)\end{array}$ & $\begin{array}{l}8.80 \\
(8.50)\end{array}$ & $\begin{array}{l}2.70 \\
(141.17)\end{array}$ & $\begin{array}{l}-12.25 \\
(-20.47)\end{array}$ & 0.991 & 0.0057 & & \\
\hline \multicolumn{9}{|c|}{ Individual Border Estimates } \\
\hline Period & $(\ln )$ dist & $\mathrm{emu}$ & nafta & $\begin{array}{l}\text { emu- } \\
\text { nafta }\end{array}$ & emu-ja & nafta-ja & $R_{a d j}^{2}$ & s.e.r. \\
\hline $\begin{array}{l}91.01- \\
94.12\end{array}$ & $\begin{array}{l}0.76 \\
(2.57)\end{array}$ & $\begin{array}{l}69.72 \\
(28.54)\end{array}$ & $\begin{array}{l}35.14 \\
(0.0)\end{array}$ & $\begin{array}{l}159.34 \\
(22.85)\end{array}$ & $\begin{array}{l}145.84 \\
(23.21)\end{array}$ & $\begin{array}{l}100.51 \\
(12.07)\end{array}$ & 0.983 & 0.0079 \\
\hline $\begin{array}{l}95.01- \\
98.12\end{array}$ & $\begin{array}{l}-0.34 \\
(-0.84)\end{array}$ & $\begin{array}{l}51.90 \\
(24.52)\end{array}$ & $\begin{array}{l}43.74 \\
(0.0)\end{array}$ & $\begin{array}{l}117.86 \\
(11.40)\end{array}$ & $\begin{array}{l}177.83 \\
(10.44)\end{array}$ & $\begin{array}{l}222.95 \\
(10.25)\end{array}$ & 0.989 & 0.0072 \\
\hline $\begin{array}{l}99.01- \\
02.12\end{array}$ & $\begin{array}{l}1.38 \\
(4.54)\end{array}$ & $\begin{array}{l}6.42 \\
(3.22)\end{array}$ & $\begin{array}{l}43.71 \\
(0.0)\end{array}$ & $\begin{array}{l}114.07 \\
(3.31)\end{array}$ & $\begin{array}{l}169.57 \\
(4.18)\end{array}$ & $\begin{array}{l}148.27 \\
(17.20)\end{array}$ & 0.995 & 0.0053 \\
\hline
\end{tabular}

\section{Notes:}

1) Table 10 reports regression results for border estimates when volatility measure 2 is employed to capture the degree of relative price volatility across regions. Volatility measure 2 is computed as the spread between the $10 \%$ and the $90 \%$ percentile of the distribution of bi-monthly relative price changes. A more detailed description of the estimation approach and terms used in the upper panel is given in table 4, a more detailed description of the estimation approach and terms used in the lower panel is given in table 7 . 
Table 11: Subcategories, Individual Border Estimates, Subperiods, Summary Results, Volatility Measure 2

\begin{tabular}{|c|c|c|c|c|c|c|}
\hline \multicolumn{7}{|c|}{ Estimated Equation: $y=\sum_{k=1}^{l} \beta_{k} * x_{i j, k}+$ regdum $+\epsilon_{i j}$} \\
\hline Period & (ln)dist & emu & nafta & $\begin{array}{l}\text { emu- } \\
\text { nafta }\end{array}$ & $R_{a d j}^{2}$ & s.e.r. \\
\hline \multicolumn{7}{|l|}{ food } \\
\hline $95.01-98.12$ & $\begin{array}{l}2.68 \\
(4.51)\end{array}$ & $\begin{array}{l}32.80 \\
(10.77)\end{array}$ & $\begin{array}{l}24.06 \\
(0.0)\end{array}$ & $\begin{array}{l}94.26 \\
(10.31)\end{array}$ & 0.970 & 0.0078 \\
\hline $99.01-02.12$ & $\begin{array}{l}1.76 \\
(3.24)\end{array}$ & $\begin{array}{l}12.35 \\
(6.55)\end{array}$ & $\begin{array}{l}26.73 \\
(0.0)\end{array}$ & $\begin{array}{l}99.11 \\
(6.64)\end{array}$ & 0.981 & 0.0069 \\
\hline \multicolumn{7}{|l|}{ alco } \\
\hline $95.01-98.12$ & $\begin{array}{l}1.21 \\
(1.12)\end{array}$ & $\begin{array}{l}47.68 \\
(14.76)\end{array}$ & $\begin{array}{l}24.64 \\
(0.0)\end{array}$ & $\begin{array}{l}97.52 \\
(12.94)\end{array}$ & 0.922 & 0.0121 \\
\hline $99.01-02.12$ & $\begin{array}{l}3.73 \\
(6.66)\end{array}$ & $\begin{array}{l}22.71 \\
(9.80)\end{array}$ & $\begin{array}{l}33.02 \\
(0.0)\end{array}$ & $\begin{array}{l}99.32 \\
(9.10)\end{array}$ & 0.980 & 0.0072 \\
\hline \multicolumn{7}{|l|}{ clot } \\
\hline $95.01-98.12$ & $\begin{array}{l}2.51 \\
(2.03)\end{array}$ & $\begin{array}{l}72.68 \\
(36.33)\end{array}$ & $\begin{array}{l}21.85 \\
(0.0)\end{array}$ & $\begin{array}{l}115.56 \\
(25.51)\end{array}$ & 0.958 & 0.0154 \\
\hline $99.01-02.12$ & $\begin{array}{l}6.17 \\
(3.4)\end{array}$ & $\begin{array}{l}98.55 \\
(38.73)\end{array}$ & $\begin{array}{l}54.01 \\
(0.0)\end{array}$ & $\begin{array}{l}138.30 \\
(36.60)\end{array}$ & 0.942 & 0.0233 \\
\hline \multicolumn{7}{|l|}{ hous } \\
\hline $95.01-98.12$ & $\begin{array}{l}0.33 \\
(0.35)\end{array}$ & $\begin{array}{l}38.19 \\
(11.93)\end{array}$ & $\begin{array}{l}32.15 \\
(0.0)\end{array}$ & $\begin{array}{l}93.45 \\
(18.57)\end{array}$ & 0.948 & 0.0118 \\
\hline $99.01-02.12$ & $\begin{array}{l}1.88 \\
(0.74)\end{array}$ & $\begin{array}{l}7.40 \\
(3.07)\end{array}$ & $\begin{array}{l}42.07 \\
(0.0)\end{array}$ & $\begin{array}{l}79.89 \\
(10.55)\end{array}$ & 0.975 & 0.0223 \\
\hline \multicolumn{7}{|l|}{ furn } \\
\hline $95.01-98.12$ & $\begin{array}{l}2.85 \\
(5.44)\end{array}$ & $\begin{array}{l}29.14 \\
(12.02)\end{array}$ & $\begin{array}{l}22.45 \\
(0.0)\end{array}$ & $\begin{array}{l}90.32 \\
(14.27)\end{array}$ & 0.974 & 0.0076 \\
\hline $99.01-02.12$ & $\begin{array}{l}0.55 \\
(1.40)\end{array}$ & $\begin{array}{l}3.28 \\
(1.62)\end{array}$ & $\begin{array}{l}35.58 \\
(0.0)\end{array}$ & $\begin{array}{l}105.80 \\
(5.49)\end{array}$ & 0.992 & 0.0050 \\
\hline \multicolumn{7}{|l|}{ heal } \\
\hline $95.01-98.12$ & $\begin{array}{l}0.62 \\
(1.30)\end{array}$ & $\begin{array}{l}41.23 \\
(16.93)\end{array}$ & $\begin{array}{l}29.59 \\
(0.0)\end{array}$ & $\begin{array}{l}97.51 \\
(11.97)\end{array}$ & 0.970 & 0.0073 \\
\hline $99.01-02.12$ & $\begin{array}{l}1.54 \\
(2.72)\end{array}$ & $\begin{array}{l}5.94 \\
(5.24)\end{array}$ & $\begin{array}{l}34.63 \\
(0.0)\end{array}$ & $\begin{array}{l}102.78 \\
(8.91)\end{array}$ & 0.972 & 0.0091 \\
\hline \multicolumn{7}{|l|}{$\operatorname{tran}$} \\
\hline $95.01-98.12$ & $\begin{array}{l}1.23 \\
(2.56)\end{array}$ & $\begin{array}{l}33.57 \\
(11.47)\end{array}$ & $\begin{array}{l}29.73 \\
(0.0)\end{array}$ & $\begin{array}{l}94.63 \\
(8.53)\end{array}$ & 0.975 & 0.0069 \\
\hline $99.01-02.12$ & $\begin{array}{l}3.66 \\
(4.97)\end{array}$ & $\begin{array}{l}14.65 \\
(6.60)\end{array}$ & $\begin{array}{l}30.06 \\
(0.0)\end{array}$ & $\begin{array}{l}95.85 \\
(9.64)\end{array}$ & 0.980 & 0.0078 \\
\hline
\end{tabular}

\section{Notes:}

1) Table 11 reports regression results of border estimates for our subcategories when volatility measure 2 is employed to capture the degree of relative price volatility across regions. Volatility measure 2 is given by the spread between the $10 \%$ and the $90 \%$ percentile of the distribution of bi-monthly relative price changes between two regions. For a more detailed description of the terms used in this table, see table 6 . 
Table 12: All Items, Aggregate and Individual Border Estimates, Volatility Measure 3

\begin{tabular}{|c|c|c|c|c|c|c|c|c|}
\hline \multicolumn{9}{|c|}{ Estimated Equation: $y=\sum_{k=1}^{l} \beta_{k} * x_{i j, k}+$ regdum $+\epsilon_{i j}$} \\
\hline \multicolumn{9}{|c|}{ Specifications 1 to 4} \\
\hline Spec & $(\ln )$ dist & border & n.e.r.vol. & intra-c. & $R_{a d j}^{2}$ & s.e.r. & & \\
\hline 1 & $\begin{array}{l}14.25 \\
(103.17)\end{array}$ & & & & 0.857 & 0.0076 & & \\
\hline 2 & $\begin{array}{l}11.73 \\
(65.82)\end{array}$ & $\begin{array}{l}11.13 \\
(18.11)\end{array}$ & & & 0.872 & 0.0072 & & \\
\hline 3 & $\begin{array}{l}0.37 \\
(4.4)\end{array}$ & $\begin{array}{l}-6.42 \\
(-24.3)\end{array}$ & $\begin{array}{l}1.06 \\
(151.81)\end{array}$ & & 0.984 & 0.0026 & & \\
\hline 4 & $\begin{array}{l}-0.18 \\
(-1.63)\end{array}$ & $\begin{array}{l}6.23 \\
(6.54)\end{array}$ & $\begin{array}{l}0.85 \\
(67.82)\end{array}$ & $\begin{array}{l}-7.87 \\
(-15.44)\end{array}$ & 0.986 & 0.0024 & & \\
\hline \multicolumn{9}{|c|}{ Individual Border Estimates } \\
\hline Period & $(\ln )$ dist & $\mathrm{emu}$ & nafta & $\begin{array}{l}\text { emu- } \\
\text { nafta }\end{array}$ & emu-ja & nafta-ja & $R_{a d j}^{2}$ & s.e.r. \\
\hline $\begin{array}{l}91.01- \\
94.12\end{array}$ & $\begin{array}{l}0.22 \\
(2.81)\end{array}$ & $\begin{array}{l}26.58 \\
(10.84)\end{array}$ & $\begin{array}{l}11.61 \\
(0.0)\end{array}$ & $\begin{array}{l}58.64 \\
(10.53)\end{array}$ & $\begin{array}{l}64.68 \\
(14.52)\end{array}$ & $\begin{array}{l}29.08 \\
(3.63)\end{array}$ & 0.996 & 0.0015 \\
\hline $\begin{array}{l}95.01- \\
98.12\end{array}$ & $\begin{array}{l}0.05 \\
(0.72)\end{array}$ & $\begin{array}{l}15.45 \\
(8.65)\end{array}$ & $\begin{array}{l}20.50 \\
(0.0)\end{array}$ & $\begin{array}{l}44.07 \\
(2.73)\end{array}$ & $\begin{array}{l}56.54 \\
(6.30)\end{array}$ & $\begin{array}{l}58.78 \\
(0.66)\end{array}$ & 0.997 & 0.0012 \\
\hline $\begin{array}{l}99.01- \\
2.12\end{array}$ & $\begin{array}{l}0.12 \\
(1.13)\end{array}$ & $\begin{array}{l}1.99 \\
(0.85)\end{array}$ & $\begin{array}{l}12.53 \\
(0.0)\end{array}$ & $\begin{array}{l}48.17 \\
(6.68)\end{array}$ & $\begin{array}{l}66.08 \\
(0.95)\end{array}$ & $\begin{array}{l}45.32 \\
(6.78)\end{array}$ & 0.995 & 0.0020 \\
\hline
\end{tabular}

\section{Notes:}

1) Table 12 reports regression results for border estimates when volatility measure 3 is employed to capture the degree of relative price volatility across regions. Volatility measure 3 is computed as the standard deviation of the cyclical component of the HP-filtered relative price series. A more detailed description of the estimation approach and terms used in the upper panel is given in table 4. a more detailed description of the estimation approach and terms used in the lower panel is given in table 7 . 
Table 13: Subcategories, Individual Border Estimates, Subperiods, Summary Results, Volatility Measure 3

\begin{tabular}{|c|c|c|c|c|c|c|}
\hline \multicolumn{7}{|c|}{ Estimated Equation: $y=\sum_{k=1}^{l} \beta_{k} * x_{i j, k}+$ regdum $+\epsilon_{i j}$} \\
\hline Period & $(\ln )$ dist & $\mathrm{emu}$ & nafta & $\begin{array}{l}\text { emu- } \\
\text { nafta }\end{array}$ & $R_{a d j}^{2}$ & s.e.r. \\
\hline \multicolumn{7}{|l|}{ food } \\
\hline $95.01-98.12$ & $\begin{array}{l}0.48 \\
(2.73)\end{array}$ & $\begin{array}{l}12.84 \\
(3.96)\end{array}$ & $\begin{array}{l}15.46 \\
(0.0)\end{array}$ & $\begin{array}{l}39.93 \\
(5.02)\end{array}$ & 0.984 & 0.0023 \\
\hline $99.01-02.06$ & $\begin{array}{l}0.38 \\
(1.71)\end{array}$ & $\begin{array}{l}4.14 \\
(2)\end{array}$ & $\begin{array}{l}7.27 \\
(0.0)\end{array}$ & $\begin{array}{l}45.41 \\
(6.85)\end{array}$ & 0.987 & 0.0027 \\
\hline \multicolumn{7}{|l|}{ alco } \\
\hline $95.01-98.12$ & $\begin{array}{l}0.41 \\
(1.48)\end{array}$ & $\begin{array}{l}11.67 \\
(2.81)\end{array}$ & $\begin{array}{l}14.72 \\
(0.0)\end{array}$ & $\begin{array}{l}36.81 \\
(5.76)\end{array}$ & 0.968 & 0.0030 \\
\hline $99.01-02.06$ & $\begin{array}{l}1.27 \\
(5.17)\end{array}$ & $\begin{array}{l}4.02 \\
(1.69)\end{array}$ & $\begin{array}{l}5.83 \\
(0.0)\end{array}$ & $\begin{array}{l}43.06 \\
(6.2)\end{array}$ & 0.985 & 0.0029 \\
\hline \multicolumn{7}{|l|}{ clot } \\
\hline $95.01-98.12$ & $\begin{array}{l}0.24 \\
(0.99)\end{array}$ & $\begin{array}{l}16.18 \\
(4.56)\end{array}$ & $\begin{array}{l}11.88 \\
(0.0)\end{array}$ & $\begin{array}{l}41.44 \\
(3.91)\end{array}$ & 0.983 & 0.0027 \\
\hline $99.01-02.06$ & $\begin{array}{l}0.95 \\
(2.62)\end{array}$ & $\begin{array}{l}17.81 \\
(7.19)\end{array}$ & $\begin{array}{l}8.57 \\
(0.0)\end{array}$ & $\begin{array}{l}42.17 \\
(6.51)\end{array}$ & 0.972 & 0.0042 \\
\hline \multicolumn{7}{|l|}{ hous } \\
\hline $95.01-98.12$ & $\begin{array}{l}0.51 \\
(1.61)\end{array}$ & $\begin{array}{l}9.76 \\
(2.81)\end{array}$ & $\begin{array}{l}20.18 \\
(0.0)\end{array}$ & $\begin{array}{l}37.00 \\
(4.91)\end{array}$ & 0.976 & 0.0032 \\
\hline $99.01-02.06$ & $\begin{array}{l}0.43 \\
(0.92)\end{array}$ & $\begin{array}{l}3.02 \\
(1.61)\end{array}$ & $\begin{array}{l}21.48 \\
(0.0)\end{array}$ & $\begin{array}{l}42.16 \\
(3.31)\end{array}$ & 0.988 & 0.0040 \\
\hline \multicolumn{7}{|l|}{ furn } \\
\hline $95.01-98.12$ & $\begin{array}{l}0.94 \\
(5.06)\end{array}$ & $\begin{array}{l}9.20 \\
(2.65)\end{array}$ & $\begin{array}{l}14.30 \\
(0.0)\end{array}$ & $\begin{array}{l}35.71 \\
(4.79)\end{array}$ & 0.983 & 0.0023 \\
\hline $99.01-02.06$ & $\begin{array}{l}0.14 \\
(0.57)\end{array}$ & $\begin{array}{l}0.82 \\
(0.38)\end{array}$ & $\begin{array}{l}8.94 \\
(0.0)\end{array}$ & $\begin{array}{l}47.31 \\
(6.82)\end{array}$ & 0.988 & 0.0028 \\
\hline \multicolumn{7}{|l|}{ heal } \\
\hline $95.01-98.12$ & $\begin{array}{l}0.13 \\
(0.57)\end{array}$ & $\begin{array}{l}15.29 \\
(7.54)\end{array}$ & $\begin{array}{l}14.55 \\
(0.0)\end{array}$ & $\begin{array}{l}36.30 \\
(4.87)\end{array}$ & 0.968 & 0.0030 \\
\hline $99.01-02.06$ & $\begin{array}{l}0.44 \\
(2.16)\end{array}$ & $\begin{array}{l}1.74 \\
(1.18)\end{array}$ & $\begin{array}{l}9.34 \\
(0.0)\end{array}$ & $\begin{array}{l}44.10 \\
(4.11)\end{array}$ & 0.984 & 0.0029 \\
\hline \multicolumn{7}{|l|}{$\operatorname{tran}$} \\
\hline $95.01-98.12$ & $\begin{array}{l}0.78 \\
(5.42)\end{array}$ & $\begin{array}{l}8.73 \\
(1.57)\end{array}$ & $\begin{array}{l}15.51 \\
(0.0)\end{array}$ & $\begin{array}{l}39.39 \\
(4.62)\end{array}$ & 0.988 & 0.0020 \\
\hline $99.01-02.06$ & $\begin{array}{l}1.60 \\
(5.94)\end{array}$ & $\begin{array}{l}3.60 \\
(2.58)\end{array}$ & $\begin{array}{l}13.64 \\
(0.0)\end{array}$ & $\begin{array}{l}41.13 \\
(10.46)\end{array}$ & 0.976 & 0.0036 \\
\hline
\end{tabular}

\section{Notes:}

1) Table 13 reports regression results of border estimates for our subcategories when volatility measure 3 is employed to capture the degree of relative price volatility across regions. Volatility measure 3 is given by the standard deviation of the cyclical component of the HP-filtered relative price series. For a more detailed description of the terms used in this table, see table 6. 
Table 14: Descriptive Statistics for Single-Equation ADF Tests

\begin{tabular}{|c|c|c|c|c|}
\hline \multicolumn{5}{|c|}{ Estimated Equation: $\Delta q_{i j, t}=\alpha_{i j}+\rho_{i j} * q_{i j, t-1}+\sum_{j=1}^{6} \phi_{i j, k} \Delta q_{i j, t-k}+\epsilon_{i j, t}$} \\
\hline \multicolumn{5}{|c|}{ Unadjusted Coefficients } \\
\hline Mean & $\begin{array}{l}\text { All } \\
0.85\end{array}$ & $\begin{array}{l}\text { Intra-Nat. } \\
0.91\end{array}$ & $\begin{array}{l}\text { Intra-Cont. } \\
0.82\end{array}$ & $\begin{array}{l}\text { Inter-Cont. } \\
0.86\end{array}$ \\
\hline Std.Dvt. & 0.08 & 0.11 & 0.09 & 0.05 \\
\hline Half-Life & 0.7 & 1.3 & 0.6 & 0.7 \\
\hline \multicolumn{5}{|c|}{ Adjusted Coefficients } \\
\hline & All & Intra-Nat. & Intra-Cont. & Inter-Cont. \\
\hline Mean & 0.91 & 0.97 & 0.87 & 0.91 \\
\hline Std.Dvt. & 0.08 & 0.11 & 0.09 & 0.05 \\
\hline Half-Life & 1.2 & 21.8 & 0.8 & 1.3 \\
\hline
\end{tabular}

\section{Notes:}

1) Table 14 reports means and standard deviations of estimated individual $\mathrm{AR}(1)$ coefficients for relative prices. $q_{i j, t}$ denotes the real exchange between region $i$ and region $j$ in period $t$. The overall number of considered relative price series is 5,987 .

2) The term 'Intra-Nat.' refers to estimated AR(1) coefficients for relative prices between regions that are located in the same country. The term 'Intra-Cont.' refers to estimated AR(1) coefficients for relative prices between regions that are in different countries but are on the same continent. The term 'Intercont.' refers to estimated AR(1) coefficients for relative price between regions that are in different countries and on different continents.

3) Bias adjustment is done using the formula by Kendall (1954).

4) Half-lives are computed using the formula: half - life $=\frac{\ln (0.5)}{\ln (\hat{\rho})}$, where $\hat{\rho}$ denotes the estimated $\operatorname{AR}(1)$ coefficient. 
Table 15: Regression Results for AR(1) Coefficients from Single-Equation Unit Root Tests

\begin{tabular}{|c|c|c|c|c|c|}
\hline \multicolumn{6}{|c|}{ Estimated Equation: $\hat{\rho}_{i j}=\sum_{k=1}^{l} \beta_{k} * x_{i j, k}+$ regdum $+\epsilon_{i j}$} \\
\hline Expl. Var. & Spec. 1 & Spec. 2 & Spec. 3 & Spec. 4 & Spec. 5 \\
\hline (ln)dist & $\begin{array}{l}-12.25 \\
(-9.39)\end{array}$ & $\begin{array}{l}14.32 \\
(9.35)\end{array}$ & $\begin{array}{l}0.00 \\
(2.68)\end{array}$ & $\begin{array}{l}7.77 \\
(3.29)\end{array}$ & $\begin{array}{l}7.30 \\
(3.17)\end{array}$ \\
\hline border & & $\begin{array}{l}-116.54 \\
(-20.20)\end{array}$ & $\begin{array}{l}-130.41 \\
(-17.98)\end{array}$ & $\begin{array}{l}-168.94 \\
(-8.91)\end{array}$ & $\begin{array}{l}-150.49 \\
(-7.95)\end{array}$ \\
\hline n.e.r.vol. & & & $\begin{array}{l}0.89 \\
(4.70)\end{array}$ & $\begin{array}{l}1.56 \\
(4.49)\end{array}$ & $\begin{array}{l}1.30 \\
(3.75)\end{array}$ \\
\hline intra-cont. & & & & $\begin{array}{l}24.05 \\
(2.62)\end{array}$ & \\
\hline EMU & & & & & $\begin{array}{l}-1.00 \\
(-0.10)\end{array}$ \\
\hline NAFTA & & & & & $\begin{array}{l}91.38 \\
(11.42)\end{array}$ \\
\hline$R_{a d j}^{2}$ & 0.296 & 0.409 & 0.413 & 0.415 & 0.431 \\
\hline s.e.r. & 0.0666 & 0.0610 & 0.0608 & 0.0607 & 0.0599 \\
\hline
\end{tabular}

\section{Notes:}

1) Table 15 reports results from estimating equation (9) in section 6 of the main text. $\hat{\rho}_{i j}$ denotes the estimated $\mathrm{AR}(1)$ coefficient from an $\mathrm{ADF}$ regression for the relative price of two regions. The expression $\sum_{k=1}^{l} \beta_{k} * x_{i j, k}$ represents the explanatory variables listed in the first column. 'regdumm' represents regional dummy variables. $\epsilon_{i j}$ is assumed to be a mean-zero innovation term. All coefficients apart from those on nominal exchange rate volatility (n.e.r.vol.) are multiplied by 1,000 . There are 5,987 observations in each regression.

2) In brackets, t-statistics are reported. In computing these statistics, White's heteroscedasticconsistent errors were used.

3) $R_{a d j}^{2}$ denotes the adjusted coefficient of determination, the term s.e.r. denotes the standard error of regression. 
Table 16: Levin-Lin Panel Unit Root Test of Real Exchange Rate Convergence

\begin{tabular}{|c|c|c|c|c|c|c|}
\hline \multicolumn{7}{|c|}{ Estimated Equation: $\Delta \tilde{q}_{i, t}=\alpha_{i}+\rho_{i} * \tilde{q}_{i, t-1}+\sum_{j=1}^{k_{i}} \phi_{i, j} \Delta \tilde{q}_{i, t-j}+\epsilon_{i, t}$} \\
\hline Group & $\rho$ & $\rho_{\text {adj }}$ & t-stat & p-value & half-life & h.l.(adj.) \\
\hline \multicolumn{7}{|c|}{ All Relative Prices } \\
\hline all & 0.904 & 0.942 & -57.53 & 0.013 & 1.1 & 1.9 \\
\hline \multicolumn{7}{|c|}{ Intra-National versus International Relative Prices } \\
\hline intra-nat. & 0.969 & 1.024 & -9.34 & 0.421 & 3.7 & - \\
\hline internat. & 0.901 & 0.939 & -55.64 & 0.016 & 1.1 & 1.8 \\
\hline \multicolumn{7}{|c|}{ Intra-Continental versus Inter-Continental Relative Prices } \\
\hline intra-cont. & 0.874 & 0.909 & -46.37 & 0.003 & 0.9 & 1.2 \\
\hline intercont. & 0.921 & 0.961 & -34.36 & 0.237 & 1.4 & 2.9 \\
\hline \multicolumn{7}{|c|}{ Intra-Continental Relative Prices } \\
\hline EMU & 0.844 & 0.878 & -50.46 & 0.0003 & 0.7 & 0.9 \\
\hline NAFTA & 0.951 & 0.998 & -10.48 & 0.051 & 2.3 & 57.7 \\
\hline \multicolumn{7}{|c|}{ Inter-Continental Relative Prices } \\
\hline $\begin{array}{l}\text { EMU- } \\
\text { NAFTA }\end{array}$ & 0.939 & 0.983 & -19.66 & 0.474 & 1.8 & 6.7 \\
\hline EMU-JA & 0.907 & 0.945 & -23.27 & 0.321 & 1.2 & 2.0 \\
\hline NAFTA-JA & 0.923 & 0.963 & -12.89 & 0.298 & 1.4 & 3.1 \\
\hline
\end{tabular}

\section{Notes:}

1) Table 16 reports results from Levin-Lin panel unit root tests of real exchange rate convergence. The real exchange rate between two regions, $q_{i}$, is computed as the ratio of the respective regions' CPI (denoted in the same currency). $\tilde{q}_{i, t}$ denotes period's $t$ deviation of $q_{i}$ from the cross-sectional mean. A more detailed description of our procedure is given in section $\mathrm{B}$ of the appendix.

2) Relative prices are grouped into various classes. 'All' refers to the group of all relative prices, 'intra-nat.' involves only intra-national relative prices, 'internat.' denotes all international relative prices, 'intra-cont' denotes all intra-continental international relative prices and 'intercont.' denotes all inter-continental international relative prices. 'EMU', 'NAFTA', 'EMU-NAFTA', 'EMU-JA' and 'NAFTA-JA' comprise all international relative prices across countries that are members of the respective economic area/country.

3) Bias adjustment is done using the formula by Nickell (1981). 
Table 17: Im-Pesaran-Shin Panel Unit Root Test of Real Exchange Rate Convergence

\begin{tabular}{|c|c|c|c|c|c|c|}
\hline \multicolumn{7}{|c|}{ Estimated Equation: $\Delta \tilde{q}_{i, t}=\alpha_{i}+\rho_{i} * \tilde{q}_{i, t-1}+\sum_{j=1}^{k_{i}} \phi_{i, j} \Delta \tilde{q}_{i, t-j}+\epsilon_{i, t}$} \\
\hline Group & $\rho$ & $\rho_{a d j}$ & (avg.) t-stat & p-value & half-life & h.l.(adj.) \\
\hline \multicolumn{7}{|c|}{ All Relative Prices } \\
\hline all & 0.878 & 0.940 & -2.06 & 0.027 & 0.9 & 1.9 \\
\hline \multicolumn{7}{|c|}{ Intra-National versus International Relative Prices } \\
\hline intra-nat. & 0.912 & 0.975 & -1.33 & 0.259 & 1.3 & 4.6 \\
\hline internat. & 0.878 & 0.940 & -2.10 & 0.033 & 0.9 & 1.9 \\
\hline \multicolumn{7}{|c|}{ Intra-Continental versus Inter-Continental Relative Prices } \\
\hline intra-cont. & 0.841 & 0.901 & -2.87 & 0.003 & 0.7 & 1.1 \\
\hline intercont. & 0.899 & 0.962 & -1.70 & 0.274 & 1.1 & 3.0 \\
\hline \multicolumn{7}{|c|}{ Intra-Continental Relative Prices } \\
\hline EMU & 0.844 & 0.878 & -2.87 & 0.003 & 0.7 & 1.1 \\
\hline NAFTA & 0.951 & 1.016 & -2.24 & 0.054 & 2.3 & -7.3 \\
\hline \multicolumn{7}{|c|}{ Inter-Continental Relative Prices } \\
\hline $\begin{array}{l}\text { EMU- } \\
\text { NAFTA }\end{array}$ & 0.900 & 0.963 & -1.53 & 0.393 & 1.1 & 3.1 \\
\hline EMU-JA & 0.907 & 0.970 & -1.75 & 0.360 & 1.2 & 3.8 \\
\hline NAFTA-JA & 0.925 & 0.989 & -1.61 & 0.413 & 1.5 & 10.4 \\
\hline
\end{tabular}

\section{Notes:}

1) Table 17 reports results from Im-Pesaran-Shin panel unit root tests of real exchange rate convergence. The real exchange rate between two regions, $q_{i}$, is computed as the ratio of the respective regions' CPI (denoted in the same currency). $\tilde{q}_{i, t}$ denotes period's $t$ deviation of $q_{i}$ from the crosssectional mean. The reported values of $\rho$ and $\rho_{a d j}$ are computed as the averages of the respectively estimated single-equation $\mathrm{AR}(1)$ coefficients. A more detailed description of our procedure is given in section $\mathrm{C}$ of the appendix.

2) Relative prices are grouped into various classes. 'All' refers to the group of all relative prices, 'intra-nat.' involves only intra-national relative prices, 'internat.' denotes all international relative prices, 'intra-cont' denotes all intra-continental international relative prices and 'intercont.' denotes all inter-continental international relative prices. 'EMU', 'NAFTA', 'EMU-NAFTA', 'EMU-JA' and 'NAFTA-JA' comprise all international relative prices across countries that are members of the respective economic area/country.

3) Bias adjustment is done using the formula given by Kendall (1954). 


\section{$9 \quad$ Figures}

Figure 1: Real Exchange Rate Dispersion vs. Distance

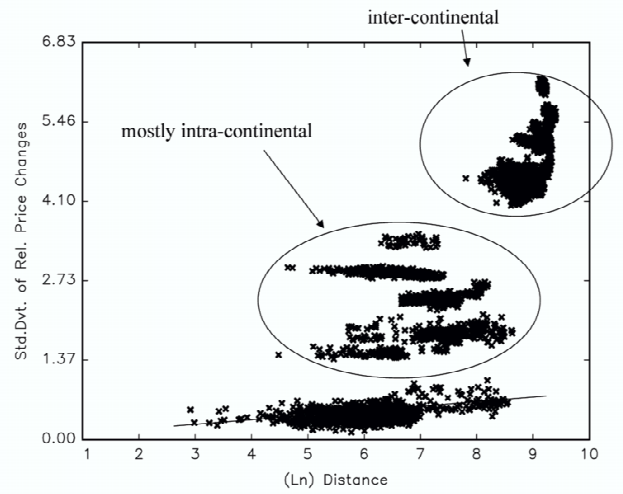

Note: Figure 1 plots our measure for relative price dispersion between two regions against the distance (in logs) between these regions. Relative price dispersion between region $i$ and region $j$ is computed as the standard deviation of two-month relative price changes, i.e.,

$$
V\left(q_{i j}\right)=\sqrt{\operatorname{var}\left(\Delta q_{i j, t}\right)}
$$

where $\Delta q_{i j, t}$ denote the two-month changes between region's $i$ and region's $j$ relative price and $\operatorname{var}($.$) denotes the empirical variance of \Delta q_{i j, t}$. The term 'intra-continental' refers to regions that are located in different countries but are members of the same continent (Europe or North-America), whereas the term 'inter-continental' refers to European-North American, European-Japanese or North American-Japanese location pairs.

Figure 2: Comparing Pre-EMU and EMU Border Effects

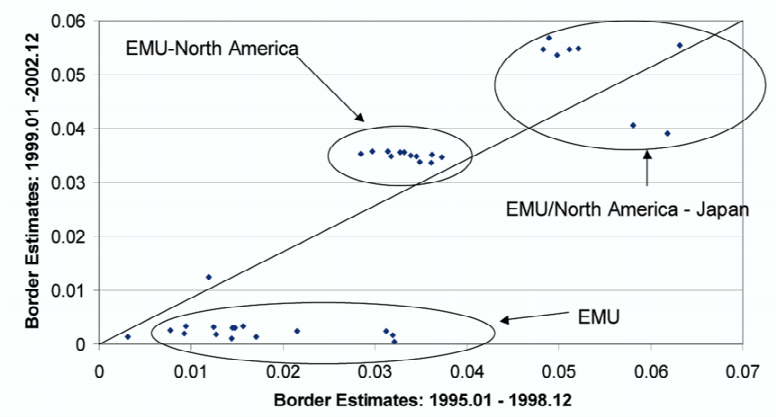

Note: Figure 2 plots our estimates for individual border effects for the pre-EMU period (1995.01-1998.12) versus their estimates for the EMU period (1999.01-2002.12). 


\section{References}

Beck, G. W. and Weber, A. A. (2001). How wide are European borders? On the integration effects of monetary unions. CFS Working Paper No. 2001/07.

Campbell, J. and Perron, P. (1991). Pitfalls and opportunities: What macroeconomists should know about unit roots. In Blanchard, O. J. and Fischer, S., editors, NBER Macroeconomics Annual 1991, pages 141-201. MIT Press, Cambridge and London.

Canzoneri, M. B., Cumby, R. E., and Diba, B. (1999). Relative labor productivity and the real exchange rate in the long run: Evidence for a panel of OECD countries. Journal of International Economics, 47:245-266.

Cecchetti, S. G., Mark, N. C., and Sonora, R. (2002). Price level convergence among United States cities: Lessons for the European Central Bank. International Economic Review, 43(4):1081-1099.

Crucini, M. J., Telmer, C. I., and Zachariadis, M. (2000). Dispersion in real exchange rates. Working Paper 01-w20, Vanderbilt - Economic and Business Administration.

Davutyan, N. and Pippenger, J. (1990). Testing purchasing power parity: Some evidence of the effects of transaction costs. Econometric Reviews, 9(2):211-240.

Devereux, M. B. and Engel, C. (1998). Fixed vs. floating exchange rates: How price setting affects the optimal choice of exchange-rate regime. NBER Working Paper No. 6867.

Dumas, B. (1992). Dynamic equilibrium and the real exchange rate in a spatially separated world. Review of Financial Studies, 5:153-180.

Engel, C., Hendrickson, M. K., and Rogers, J. H. (1997). Intra-national, intracontinental and intra-planetary PPP. Journal of the Japanese and International Economies, 11:480-501.

Engel, C. and Rogers, J. H. (1996). How wide is the border? American Economic Review, 86:1112-1125.

Engel, C. and Rogers, J. H. (2000). Relative price volatility: What role does the border play? In Hess, G. and van Wincoop, E., editors, Intranational Macroeconomics, pages 92-111. Cambridge University Press.

Engel, C. and Rogers, J. H. (2001). Deviations from purchasing power parity: Causes and welfare costs. Journal of International Economics, 55:29-57. 
Engel, C. and Rose, A. K. (2002). Currency unions and international integration. Journal of Money, Credit and Banking, 34:1067-1089.

Goldberg, P. K. and Verboven, F. (2001). Market integration and convergence to the law of one price: Evidence from the European car market. NBER Working Paper Series No. 8402.

Hall, A. R. (1994). Testing for a unit root in time series with pretest data-based model selection. Journal of Business and Economic Statistics, 12:461-470.

Hufbauer, G. C., Rogers, J. H., and Wada, E. (2001). Prive level convergence and inflation in Europe. Institute for International Economics Working Paper No. 01-1, Washington, D.C.

Im, K. S., Pesaran, H. M., and Shin, Y. (2002). Testing for unit roots in heterogeneous panels. Journal of Econometrics.

Kendall, M. (1954). Note on bias in the estimation of autocorrelation. Biometrika, 41:403-404.

Levin, A. and Lin, C.-F. (1992). Unit root tests in panel data: Asymptotic and finite-sample properties. University of California, San Diego Discussion Papers No. 92-93.

Levin, A. and Lin, C.-F. (1993). Unit root tests in panel data: New results. University of California, San Diego Discussion Papers No. 93-56.

Levin, A., Lin, C.-F., and Chu, C. (2002). Unit roots in panel data: Asymptotic and finite-sample properties. Journal of Econometrics, 108:1-24.

Mussa, M. (1986). Nominal exchange rate regimes and the behavior of real exchange rate: Evidence and implications. Carnegie Rochester Conference Series on Public Policy, 25:117-214.

Nickell, S. J. (1981). Biases in dynamic models with fixed effects. Econometrica, 49:1417-1426.

O'Connell, P. G. and Wei, S.-J. (1997). The bigger they are, the harder they fall: How price differences across U.S. cities are arbitraged. NBER Working Paper Series No. 6089 .

Parsley, D. C. and Wei, S.-J. (1996). Convergence to the law of one price without trade barriers or currency fluctuations. Quarterly Journal of Economics, 111:12111236. 
Parsley, D. D. and Wei, S.-J. (2001a). Explaining the border effect: The role of exchange rate variability, shipping costs, and geography. Journal of International Economics, 55(1):87-106.

Parsley, D. D. and Wei, S.-J. (2001b). Limiting currency volatility to stimulate goods market integration: A price based approach. NBER Working Paper Series No. 8468 .

Rogers, J. H. and Smith, H. P. (2001). Border effects within the NAFTA countries. Board of Governors of the Federal Reserve System - International Finance Discussion Papers No. 698. 


\section{A Tables}

Table A: All Items and Subcategories, Detailed Results for Individual Border Effects, 1995.01-2002.12

\begin{tabular}{|c|c|c|c|c|c|c|c|c|}
\hline & allit & food & alco & clot & hous & furn & heal & $\operatorname{tran}$ \\
\hline $\ln ($ dist $)$ & 0.10 & 0.64 & 0.33 & 1.25 & 0.53 & 0.46 & 0.37 & 0.84 \\
\hline germ-aust & 2.17 & & & & & & & \\
\hline germ-finl & 6.67 & 5.77 & 7.63 & 35.99 & 5.40 & 4.85 & 12.69 & 5.68 \\
\hline germ-ital & 21.66 & 7.40 & 11.25 & 4.54 & 6.13 & 6.23 & 12.3 & 6.43 \\
\hline germ-spai & 8.55 & 9.57 & 12.70 & 17.26 & 5.43 & 7.31 & 12.93 & 7.67 \\
\hline germ-port & 9.69 & 7.34 & 8.27 & 29.64 & 7.83 & 8.04 & 13.55 & 8.89 \\
\hline germ-usa & 34.00 & 26.93 & 30.26 & 37.90 & 28.87 & 30.14 & 28.92 & 27.85 \\
\hline germ-cana & 35.78 & 30.05 & 34.67 & 28.50 & 28.78 & 34.49 & 32.50 & 30.53 \\
\hline germ-japa & 51.57 & & & & & & & \\
\hline aust-finl & 6.08 & & & & & & & \\
\hline aust-ital & 21.34 & & & & & & & \\
\hline aust-spai & 8.19 & & & & & & & \\
\hline aust-port & 8.98 & & & & & & & \\
\hline aust-usa & 34.23 & & & & & & & \\
\hline aust-cana & 35.99 & & & & & & & \\
\hline aust-japa & 50.37 & & & & & & & \\
\hline finl-ital & 21.27 & 6.79 & 12.73 & 39.68 & 9.32 & 5.86 & 8.16 & 7.01 \\
\hline finl-spai & 10.04 & 9.47 & 14.17 & 34.38 & 8.73 & 8.01 & 8.76 & 7.86 \\
\hline finl-port & 10.55 & 8.15 & 8.90 & 30.81 & 10.36 & 7.77 & 9.89 & 9.25 \\
\hline finl-usa & 33.89 & 27.06 & 29.87 & 37.53 & 30.03 & 28.89 & 31.30 & 26.06 \\
\hline finl-cana & 35.02 & 29.96 & 33.24 & 39.67 & 29.41 & 32.57 & 33.84 & 27.80 \\
\hline finl-japa & 50.97 & & & & & & & \\
\hline ital-spai & 14.65 & 5.44 & 13.56 & 19.40 & $4.7 \xi$ & 3.99 & 3.64 & 5.74 \\
\hline ital-port & 11.27 & 4.73 & 7.55 & 32.80 & 5.47 & 4.02 & 3.94 & 4.18 \\
\hline ital-usa & 32.67 & 27.32 & 30.28 & 40.91 & 27.33 & 28.01 & 27.40 & 27.59 \\
\hline ital-cana & 34.56 & 31.56 & 34.07 & 29.83 & 29.17 & 31.89 & 30.93 & 29.49 \\
\hline ital-japa & 60.22 & & & & & & & \\
\hline spai-port & 5.46 & 4.64 & 8.16 & 27.20 & 5.06 & 3.80 & 3.14 & 8.07 \\
\hline spai-usa & 33.24 & 28.23 & 27.85 & 41.54 & 28 & 0 & 33 & 25.35 \\
\hline spai-cana & 34.55 & 32.29 & 31.35 & 31.03 & 27.87 & 31.34 & 31.66 & 27.46 \\
\hline spai-japa & 52.09 & & & & & & & \\
\hline port-usa & 31.73 & 23.32 & 25.63 & 49.33 & 26.95 & 25.66 & 27.32 & 27.94 \\
\hline port-cana & 33.54 & 27.75 & 29.31 & 41.17 & 2765 & 2082 & 30.19 & 29.95 \\
\hline port-japa & 52.92 & & & & & & & \\
\hline usa-cana & 12.30 & 8.53 & 8.35 & 12.43 & 11.33 & 7.91 & 9.38 & 8.37 \\
\hline usa-japa & 53.27 & & & & & & & \\
\hline cana-japa & 51.19 & & & & & & & \\
\hline$R_{a d j}^{2}$ & 0.998 & 0.993 & 0.986 & 0.967 & 0.994 & 0.996 & 0.990 & 0.993 \\
\hline s.e.r. & 0.0009 & 0.0012 & 0.0016 & 0.0044 & 0.0025 & 0.0009 & 0.0014 & 0.0012 \\
\hline
\end{tabular}

Notes:

1) Country short names are as follows: germ $=$ Germany, aust $=$ Austria, finl $=$ Finland, ital $=$ Italy, spai $=$ Spain, port $=$ Portugal, usa $=$ U.S.A, cana $=$ Canada, japa $=$ Japan.

2) Bold-face letters denote significant values (5\% significance level). All numbers are multiplied by 1,000. For further notes, see tables 5 and 6 . 
Table B: All Items and Subcategories, Detailed Results for Individual Border Effects, 1995.01-1998.12

\begin{tabular}{|c|c|c|c|c|c|c|c|c|}
\hline & allit & food & alco & clot & hous & furn & heal & $\operatorname{tran}$ \\
\hline $\ln$ (dist) & 0.01 & 0.66 & 0.07 & 0.94 & 0.44 & 0.69 & 0.24 & 0.44 \\
\hline $\begin{array}{l}\text { germ-aust } \\
\text { germ-finl }\end{array}$ & $\begin{array}{l}0.14 \\
9.39\end{array}$ & 9.31 & 11.2 & 29.6 & 8.11 & 7.93 & 18.58 & 8.61 \\
\hline germ-ital & 31.95 & 12.29 & 14.66 & 9.57 & 0.26 & 10.72 & 21.97 & 9.23 \\
\hline germ-spai & 12.46 & 12.54 & 16.88 & 10.24 & 8.89 & 11.43 & 19.94 & 11.07 \\
\hline germ-port & 14.5 & 11.18 & 12.08 & 23.82 & 12.90 & 12.65 & 21.16 & 12.61 \\
\hline germ-usa & 33.22 & 28.41 & 31.59 & 29.86 & 29.52 & 28.47 & 27.22 & 27.81 \\
\hline gern & 36.17 & 31.27 & 35.85 & 29.59 & 28.96 & 34.53 & 29.60 & 32.23 \\
\hline germ-japa & 48.90 & & & & & & & \\
\hline aust-fir & 9.29 & & & & & & & \\
\hline aust-i & 32.09 & & & & & & & \\
\hline ai & 12.7 & & & & & & & \\
\hline al & 14.4 & & & & & & & \\
\hline aust-u & 34.47 & & & & & & & \\
\hline $\mathrm{a}$ & 37.2 & & & & & & & \\
\hline al & 48.30 & & & & & & & \\
\hline 111 & 31.19 & 10.97 & 17.29 & 32.64 & 15 & 10.17 & 14.01 & 10.66 \\
\hline finl- & 14.72 & 11. & 19. & & & & & 12 \\
\hline finl- & 15.67 & 11.64 & 12.41 & 24. & 15 & 12. & & 11.94 \\
\hline finl- & 34.8 & 26.23 & 29.57 & 40 & & 27 & & 27.26 \\
\hline finl-ce & 36.12 & 29.14 & 32.39 & 42.68 & 30.6 & 32.54 & 34.1 & 30.19 \\
\hline finl-ja & 49.79 & & & & & & & \\
\hline ital- & 21.56 & 20 & 18.06 & 6.82 & 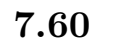 & & 7.3 & 6.75 \\
\hline ital-p & 17.10 & 8.19 & 1.40 & 4 & 9 & & 7. & 6.49 \\
\hline ital- & 29.7 & 26.79 & & & & & 77 & 24.85 \\
\hline ital & 32.6 & 31.85 & 30.93 & 28.36 & 24.81 & 29.81 & 28.22 & 30.15 \\
\hline & 63.1 & & & & & & & \\
\hline spai-port & 7.74 & & & & & & & \\
\hline spai-1 & 31.41 & & & & & & & 26.03 \\
\hline spai-cana & 33.9 & 30.19 & 31.48 & 28.33 & 27.30 & 29.36 & 29.41 & 29.69 \\
\hline & & & & & & & & \\
\hline port-usa & 28.4 & 19.9 & 3 & & 22 & & & 23.64 \\
\hline port & 31.7 & 25.26 & 27. & 37. & 23. & 26.4 & 26.91 & 27.91 \\
\hline port & 52.1 & & & & & & & \\
\hline usa-cana & 11.92 & 8.09 & 8.10 & 6.73 & 7.49 & 6.29 & 8.94 & 7.98 \\
\hline & 61.8 & & & & & & & \\
\hline cana-japa & 58.06 & & & & & & & \\
\hline$R_{a d j}^{2}$ & 0.997 & 0.986 & 0.965 & 0.972 & 0.977 & 0.989 & 0.981 & 0.993 \\
\hline s.e.r. & 0.0011 & 0.0015 & 0.0024 & 0.0035 & 0.0023 & 0.0014 & 0.0017 & 0.0011 \\
\hline
\end{tabular}

Notes:

1) Country short names are as follows: germ $=$ Germany, aust $=$ Austria, finl $=$ Finland, ital $=$ Italy, spai $=$ Spain, port $=$ Portugal, usa $=$ U.S.A, cana $=$ Canada, japa $=$ Japan.

2) Bold face letters denote significant values (5\% significance level). All numbers are multiplied by 1,000. For further notes, see tables 7 and 8 . 
Table C: All Items and Subcategories, Detailed Results for Individual Border Effects, 1999.01-2012.12

\begin{tabular}{|c|c|c|c|c|c|c|c|c|}
\hline & allit & food & alco & clot & hous & furn & heal & $\operatorname{tran}$ \\
\hline $\ln ($ dist $)$ & 0.21 & 0.56 & 0.72 & 1.54 & 0.66 & 0.24 & 0.43 & 1.14 \\
\hline zust & 1.29 & & & & & & & \\
\hline germ-finl & 3.29 & .05 & .92 & 40.58 & 2.21 & 0.56 & 3.41 & 2.85 \\
\hline germ-ital & 1.73 & 3.42 & 7.93 & -0.80 & 1.74 & 0.40 & .08 & 3.63 \\
\hline germ-spai & 3.22 & 6.96 & 7.44 & 22.89 & 0.81 & 0.94 & 0.07 & 4.50 \\
\hline germ-port & 2.97 & 58 & 3.85 & 32.86 & 0.63 & .64 & 0.39 & 5.38 \\
\hline germ-usa & 35.54 & 26.95 & 29.77 & 45.57 & 29.26 & 32.86 & 29.95 & 29.30 \\
\hline germ & 35.22 & 29.08 & 33.46 & 27.32 & 30.04 & 34.25 & 33.05 & 29.63 \\
\hline germ-japa & 56.78 & & & & & & & \\
\hline aust-finl & 2.00 & & & & & & & \\
\hline aust-it & 0.53 & & & & & & & \\
\hline i & 1.85 & & & & & & & \\
\hline aust-port & 1.09 & & & & & & & \\
\hline aust-usa & 34.87 & & & & & & & \\
\hline aust-c & 34.69 & & & & & & & \\
\hline aust-ja & 54.77 & & & & & & & \\
\hline finl-it & 2.37 & 3.15 & 7.29 & 43.17 & 2.73 & 0.32 & 3.05 & 3.81 \\
\hline finl-s & 3.06 & 6.95 & 6.51 & & 1.80 & J & & 2.73 \\
\hline finl-port & 3.32 & 4.29 & 4.16 & 7.31 & 3.40 & .05 & 63 & 7.14 \\
\hline finl- $\mathrm{c}$ & 33.73 & 29.15 & 54 & 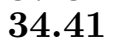 & 29.08 & & 60 & 26.25 \\
\hline finl- & 33.70 & 31.10 & 33.58 & 33.34 & 29.4 & 32.34 & 33.82 & 25.76 \\
\hline finl- & 53.63 & & & & & & & \\
\hline ital-s & 2.46 & 2.1 & 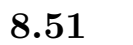 & & 1.92 & & 0 & 4.26 \\
\hline ital- & 1.39 & 1 & & & & & & 2.23 \\
\hline ital- & 35.82 & 28.65 & 31.85 & 48. & 29.03 & 32.03 & 29.43 & 30.22 \\
\hline ital & 35.68 & 31.37 & 35.00 & 29. & 29 & 33.07 & 32.83 & 29.00 \\
\hline ital- & 55.42 & & & & & & & \\
\hline spai-port & 2.52 & 2.8 & 3.91 & 31.09 & 2. & & & \\
\hline spai-usa & 35.70 & 31.3 & & & & & & 26.20 \\
\hline spai-cana & 34.99 & 34.49 & 31.61 & 34.09 & 28.99 & 32.89 & 33.69 & 26.03 \\
\hline $1 .$. & 54.6 & & & & & & & \\
\hline port-usa & 35.28 & 2 & 28.10 & & & & & 33.01 \\
\hline port-cana & 34.83 & 30.15 & 30. & 41.71 & 31 & 22 & 33.30 & 32.57 \\
\hline port- & 54.86 & & & & & & & \\
\hline usa-cana & 12.41 & 8.36 & 8.46 & 17.13 & 14.43 & 9.10 & 9.62 & 8.70 \\
\hline usa-japa & 39.04 & & & & & & & \\
\hline cana-japa & 40.63 & & & & & & & \\
\hline$R_{a d j}^{2}$ & 0.998 & 0.991 & 0.992 & 0.957 & 0.994 & 0.996 & 0.989 & 0.988 \\
\hline s.e.r. & 0.0009 & 0.0014 & 0.0015 & 0.0058 & 0.0034 & 0.0011 & 0.0017 & 0.0018 \\
\hline
\end{tabular}

Notes:

1) Country short names are as follows: germ $=$ Germany, aust $=$ Austria, finl $=$ Finland, ital $=$ Italy, spai $=$ Spain, port $=$ Portugal, usa $=$ U.S.A, cana $=$ Canada, japa $=$ Japan.

2) Bold face letters denote significant values (5\% significance level). All numbers are multiplied by 1,000. For further notes, see tables 7 and 8 . 
Table D: All Items, Aggregate and Individual Border Estimates, Quadratic Distance Function, Volatility Measure 1

\begin{tabular}{|c|c|c|c|c|c|c|c|c|c|}
\hline \multicolumn{10}{|c|}{ Estimated Equation: $y=\sum_{k=1}^{l} \beta_{k} * x_{i j, k}+$ regdum $+\epsilon_{i j}$} \\
\hline \multicolumn{10}{|c|}{ Specifications 1 to 4} \\
\hline Spec & dist & $\operatorname{dist}^{2}$ & border & n.e.r.vol. & intra-c. & $R_{a d j}^{2}$ & s.e.r. & & \\
\hline 1 & $\begin{array}{l}8.89 \\
(65.71)\end{array}$ & $\begin{array}{l}-0.39 \\
(-32.9)\end{array}$ & & & & 0.897 & 0.0059 & & \\
\hline 2 & $\begin{array}{l}6.03 \\
(52.60)\end{array}$ & $\begin{array}{l}-0.22 \\
(-22.5)\end{array}$ & $\begin{array}{l}16.18 \\
(50.82)\end{array}$ & & & 0.945 & 0.0043 & & \\
\hline 3 & $\begin{array}{l}0.12 \\
(3.51)\end{array}$ & $\begin{array}{l}0.01 \\
(5.23)\end{array}$ & $\begin{array}{l}-0.94 \\
(-5.2)\end{array}$ & $\begin{array}{l}0.91 \\
(156.22)\end{array}$ & & 0.996 & 0.0012 & & \\
\hline 4 & $\begin{array}{l}-0.19 \\
(-3.6)\end{array}$ & $\begin{array}{l}0.03 \\
(8.0)\end{array}$ & $\begin{array}{l}1.84 \\
(3.62)\end{array}$ & $\begin{array}{l}0.87 \\
(98.98)\end{array}$ & $\begin{array}{l}1.84 \\
(3.62)\end{array}$ & 0.996 & 0.0011 & & \\
\hline \multicolumn{10}{|c|}{ Individual Border Estimates } \\
\hline Period & dist & $\mathrm{dist}^{2}$ & emu & nafta & $\begin{array}{l}\text { emu- } \\
\text { nafta }\end{array}$ & emu-ja & nafta-ja & $R_{a d j}^{2}$ & s.e.r. \\
\hline $\begin{array}{l}91.01- \\
94.12\end{array}$ & $\begin{array}{l}0.08 \\
(1.17)\end{array}$ & $\begin{array}{l}-0.004 \\
(-0.79)\end{array}$ & $\begin{array}{l}21.01 \\
(8.27)\end{array}$ & $\begin{array}{l}11.39 \\
(0.0)\end{array}$ & $\begin{array}{l}46.81 \\
(4.82)\end{array}$ & $\begin{array}{l}43.70 \\
(6.92)\end{array}$ & $\begin{array}{l}30.50 \\
(3.64)\end{array}$ & 0.995 & 0.0013 \\
\hline $\begin{array}{l}95.01- \\
98.12\end{array}$ & $\begin{array}{l}0.15 \\
(1.67)\end{array}$ & $\begin{array}{l}-0.03 \\
(-4.42)\end{array}$ & $\begin{array}{l}16.45 \\
(8.96)\end{array}$ & $\begin{array}{l}11.92 \\
(0.0)\end{array}$ & $\begin{array}{l}33.80 \\
(2.61)\end{array}$ & $\begin{array}{l}53.45 \\
(5.64)\end{array}$ & $\begin{array}{l}61.27 \\
(2.90)\end{array}$ & 0.997 & 0.0011 \\
\hline $\begin{array}{l}99.01- \\
02.12\end{array}$ & $\begin{array}{l}0.27 \\
(3.16)\end{array}$ & $\begin{array}{l}-0.02 \\
(-3.01)\end{array}$ & $\begin{array}{l}2.22 \\
(0.85)\end{array}$ & $\begin{array}{l}12.40 \\
(0.0)\end{array}$ & $\begin{array}{l}34.78 \\
(0.71)\end{array}$ & $\begin{array}{l}54.90 \\
(1.05)\end{array}$ & $\begin{array}{l}39.75 \\
(1.08)\end{array}$ & 0.998 & 0.0009 \\
\hline
\end{tabular}

\section{Notes:}

1) Table $D$ reports regression results for border estimates when volatility measure 1 is employed and a quadratic distance specification is used. Volatility measure 1 is computed as the standard deviation of two-month relative price changes between the two regions. A more detailed description of the estimation approach and terms used in the upper panel is given in table 4, a more detailed description of the estimation approach and terms used in the lower panel is given in table 7 . Coefficients for dist are multiplied by $10^{6}$, coefficients for dist ${ }^{2}$ are multiplied by $10^{9}$ and border coefficients are multiplied by $10^{3}$. 
Table E: Subcategories, Individual Border Estimates, Quadratic Distance Function, Subperiods, Summary Results, Volatility Measure 1

\begin{tabular}{|c|c|c|c|c|c|c|c|}
\hline \multicolumn{8}{|c|}{ Estimated Equation: $y=\sum_{k=1}^{l} \beta_{k} * x_{i j, k}+$ regdum $+\epsilon_{i j}$} \\
\hline Period & dist & dist $^{2}$ & emu & nafta & emu-nafta & $R_{a d j}^{2}$ & s.e.r. \\
\hline food & \multirow{3}{*}{$\begin{array}{l}0.49 \\
(3.34) \\
0.63 \\
(4.21)\end{array}$} & \multirow{3}{*}{$\begin{array}{l}-0.02 \\
(-1.61) \\
-0.05 \\
(-4.43)\end{array}$} & \multirow{3}{*}{$\begin{array}{l}10.62 \\
(2.13) \\
3.89 \\
(1.84)\end{array}$} & \multirow{3}{*}{$\begin{array}{l}8.11 \\
(0.0) \\
8.39 \\
(0.0)\end{array}$} & \multirow{3}{*}{$\begin{array}{l}27.04 \\
(3.53) \\
30.21 \\
(2.16)\end{array}$} & \multirow[b]{2}{*}{0.986} & \multirow[b]{2}{*}{0.0015} \\
\hline $95.01-98.12$ & & & & & & & \\
\hline 99.01-02.06 & & & & & & 0.991 & 0.0014 \\
\hline $\begin{array}{l}\text { alco } \\
95.01-98.12\end{array}$ & \multirow{3}{*}{$\begin{array}{l}-0.41 \\
(-1.96) \\
0.65 \\
(4.63)\end{array}$} & \multirow{3}{*}{$\begin{array}{l}0.07 \\
(3.64) \\
-0.08 \\
(-7.07)\end{array}$} & \multirow{3}{*}{$\begin{array}{l}14.87 \\
(3.25) \\
6.21 \\
(2.01)\end{array}$} & \multirow{3}{*}{$\begin{array}{l}8.11 \\
(0.0) \\
8.60 \\
(0.0)\end{array}$} & \multirow{3}{*}{$\begin{array}{l}29.27 \\
(3.45) \\
33.13 \\
(2.13)\end{array}$} & 0.966 & 0.0024 \\
\hline 99.01-02.06 & & & & & & 0.992 & 0.0014 \\
\hline clot & & & & & & & \\
\hline $95.01-98.12$ & \multirow{2}{*}{$\begin{array}{l}0.92 \\
(1.93) \\
2.38 \\
(4.8)\end{array}$} & \multirow{2}{*}{$\begin{array}{l}-0.12 \\
(-2.92) \\
-0.24 \\
(-6.14)\end{array}$} & \multirow{2}{*}{$\begin{array}{l}22.31 \\
(9.75) \\
30.01 \\
(12.32)\end{array}$} & \multirow{2}{*}{$\begin{array}{l}6.91 \\
(0.0) \\
17.20 \\
(0.0)\end{array}$} & \multirow{2}{*}{$\begin{array}{l}35.93 \\
(5.32) \\
41.72 \\
(10.8)\end{array}$} & 0.972 & 0.0035 \\
\hline 99.01-02.06 & & & & & & 0.957 & 0.0057 \\
\hline $\begin{array}{l}\text { hous } \\
95.01-98.12\end{array}$ & \multirow{4}{*}{$\begin{array}{l}0.95 \\
(3.21) \\
0.68 \\
(1.21)\end{array}$} & \multirow{4}{*}{$\begin{array}{l}-0.16 \\
(-5.57) \\
-0.06 \\
(-1.35)\end{array}$} & \multirow{4}{*}{$\begin{array}{l}10.96 \\
(3.19) \\
2.14 \\
(0.78)\end{array}$} & \multirow{4}{*}{$\begin{array}{l}7.62 \\
(0.0) \\
14.48 \\
(0.0)\end{array}$} & \multirow{4}{*}{$\begin{array}{l}30.12 \\
(3.14) \\
29.83 \\
(0.94)\end{array}$} & 0.979 & 0.0022 \\
\hline & & & & & & & \\
\hline 99.01-02.06 & & & & & & 0.994 & 0.0034 \\
\hline furn & & & & & & & \\
\hline $95.01-98.12$ & \multirow{3}{*}{$\begin{array}{l}1.19 \\
(7.33) \\
0.28 \\
(2.15)\end{array}$} & \multirow{3}{*}{$\begin{array}{l}-0.15 \\
(-10.33) \\
-0.04 \\
(-3.48)\end{array}$} & \multirow{3}{*}{$\begin{array}{l}9.52 \\
(2.69) \\
0.88 \\
(0.38)\end{array}$} & \multirow{3}{*}{$\begin{array}{l}6.37 \\
(0.0) \\
9.15 \\
(0.0)\end{array}$} & \multirow{3}{*}{$\begin{array}{l}29.38 \\
(3.96) \\
33.28 \\
(0.83)\end{array}$} & 0.991 & 14 \\
\hline 99.01-02.06 & & & & & & 0.997 & 0.0010 \\
\hline heal & & & & & & & \\
\hline $95.01-98.12$ & \multirow{2}{*}{$\begin{array}{l}0.14 \\
(1.1) \\
0.67 \\
(4.74)\end{array}$} & \multirow{2}{*}{$\begin{array}{l}0.00 \\
(0.33) \\
-0.07 \\
(-5.66)\end{array}$} & \multirow{2}{*}{$\begin{array}{l}14.64 \\
(6.06) \\
1.67 \\
(1.31)\end{array}$} & \multirow{2}{*}{$\begin{array}{l}8.93 \\
(0.0) \\
9.64 \\
(0.0)\end{array}$} & \multirow{2}{*}{$\begin{array}{l}28.28 \\
(3.04) \\
32.21 \\
(1.48)\end{array}$} & 0.981 & 0.0017 \\
\hline 99.01-02.06 & & & & & & 0.989 & 0.0017 \\
\hline $\begin{array}{l}\operatorname{tran} \\
95.01-98.12\end{array}$ & \multirow{2}{*}{$\begin{array}{l}0.33 \\
(3.04) \\
1.10 \\
(5.16)\end{array}$} & \multirow{2}{*}{$\begin{array}{l}-0.03 \\
(-3.34) \\
-0.06 \\
(-2.99)\end{array}$} & $\begin{array}{l}10.08 \\
(2.38)\end{array}$ & $\begin{array}{l}8.03 \\
(0.0)\end{array}$ & $\begin{array}{l}28.40 \\
(2.61)\end{array}$ & 0.992 & 0.0011 \\
\hline 99.01-02.06 & & & $\begin{array}{l}4.87 \\
(2.01)\end{array}$ & $\begin{array}{l}8.69 \\
(0.0)\end{array}$ & $\begin{array}{l}27.69 \\
(2.7)\end{array}$ & 0.988 & 0.0018 \\
\hline
\end{tabular}

\section{Notes:}

1) Table E reports regression results of border estimates for our subcategories when volatility measure 1 is employed and a quadratic distance specification is used. Volatility Measure 1 is computed as the standard deviation of two-month relative price changes between the two regions. For a more detailed description of the terms used in this table, see table 6. Coefficients for dist are multiplied by $10^{6}$, coefficients for dist $^{2}$ are multiplied by $10^{9}$ and border coefficients are multiplied by $10^{3}$. 


\section{B Levin-Lin Panel Unit Root Test}

\section{B.1 The Test Procedure}

To obtain the Levin-Lin panel-unit root results in section 6, we proceed as follows: Let $q_{i, t}$ (with $i=1,2, \ldots, N$ and $t=1,2, \ldots, T$ ) be a balanced panel of real exchange rates consisting of $N$ individual regions with $T$ observations, respectively. The starting point of our analysis is the following test equation:

$$
\Delta q_{i, t}=\rho_{i} q_{i, t-1}+u_{i, t}
$$

where $-2<\rho_{i} \leq 0$, and $u_{i, t}$ has the following error-components representation

$$
u_{i, t}=\alpha_{i}+\theta_{t}+\epsilon_{i, t}
$$

In this specification, $\alpha_{i}$ represents an individual-specific effect, $\theta_{t}$ represents a commontime effect and $\epsilon_{i, t}$ is a (possibly serially correlated) stationary idiosyncratic shock. The Levin-Lin test procedure imposes (both for the null hypothesis of non-stationarity and for the alternative hypothesis of stationarity) the homogeneity restriction that all $\rho_{i}$ are equal across individual regions. Thus, the null hypothesis can be formulated as:

$$
H_{0}: \rho_{1}=\rho_{2}=\cdots=\rho_{N}=\rho=0,
$$

and the alternative hypothesis (that all series are stationary) is given by:

$$
H_{1}: \rho_{1}=\rho_{2}=\cdots=\rho_{N}=\rho<0 .
$$

To test this null hypothesis we proceed as follows:

1. First, we control for the common-time effect by subtracting the cross-sectional means:

$$
\tilde{q}_{i, t}=q_{i, t}-\frac{1}{N} \sum_{j=1}^{N} q_{j, t}
$$

Having transformed the dependent variable we proceed with the following test equation:

$$
\Delta \tilde{q}_{i, t}=\alpha_{i}+\rho \tilde{q}_{i, t-1}+\sum_{j=1}^{k_{i}} \phi_{i, j} \Delta \tilde{q}_{i, t-j}+\epsilon_{i, t} .
$$

The lagged differences of $\tilde{q}_{i, t}$ are included to control for potential serial correlations in the idiosyncratic shocks $\epsilon_{i, t}$. Whereas we equalize $\rho_{i}$ across individuals we allow for different degrees of serial correlation, $k_{i}$ (with $i=1, \ldots, N$ ), across them. The number of lagged differences for each region is determined by the general-to-specific 
method of Hall (1994) which is recommended by Campbell and Perron (1991).

2. The next step in our testing procedure is to run the following two auxiliary regressions

$$
\begin{gathered}
\Delta \tilde{q}_{i, t}=\alpha_{1 i}+\sum_{j=1}^{k_{i}} \phi_{1 i, j} \Delta \tilde{q}_{i, t-j}+e_{i, t} . \\
\tilde{q}_{i, t-1}=\alpha_{2 i}+\sum_{j=1}^{k_{i}} \phi_{2 i, j} \Delta \tilde{q}_{i, t-j}+\nu_{i, t-1} .
\end{gathered}
$$

and to retrieve the residuals $\hat{e}_{i, t}$ and $\hat{\nu}_{i, t-1}$ from these regressions.

3. These residuals are used to run the regression

$$
\hat{e}_{i, t}=\rho_{i} \hat{\nu}_{i, t-1}+\eta_{i, t}
$$

The residuals of (B.7) are used to compute an estimate of the variance of $\eta_{i, t}$ :

$$
\hat{\sigma}_{\eta i}^{2}=\frac{1}{T-k_{i}-1} \sum_{t=k_{i}+2}^{T} \hat{\eta}_{i, t}^{2}
$$

4. Normalizing the OLS residuals $\hat{e}_{i, t}$ and $\hat{\nu}_{i, t-1}$ by dividing them through $\hat{\sigma}_{\eta i}$ yields:

$$
\begin{aligned}
\tilde{e}_{i, t} & =\frac{\hat{e}_{i, t}}{\hat{\sigma}_{\eta i}} \\
\tilde{\nu}_{i, t-1} & =\frac{\hat{\nu}_{i, t-1}}{\hat{\sigma}_{\eta i}}
\end{aligned}
$$

5. The normalized residuals are used to run the following pooled cross-section time-series regression:

$$
\tilde{e}_{i, t}=\rho \tilde{\nu}_{i, t-1}+\tilde{\epsilon}_{i, t}
$$

Under the null hypothesis,- $\tilde{e}_{i, t}$ is independent of $\tilde{\nu}_{i, t-1}$, i.e., we can test the null hypothesis by testing whether $\rho=0$. Unfortunately, the studentized coefficient

$$
\tau=\frac{\hat{\rho}}{\hat{\sigma}_{\tilde{\epsilon}} \sum_{i=1}^{N} \sum_{t=2+k_{i}}^{T} \tilde{\nu}_{i, t-1}^{2}}
$$

with

$$
\hat{\sigma}_{\tilde{\epsilon}}=\frac{1}{N T} \sum_{i=1}^{N} \sum_{t=2+k_{i}}^{T} \tilde{\epsilon}_{i, t}
$$

is not asymptotically normally distributed. Levin and Lin (1993) compute an 
adjusted test statistic based on $\tau$ that it is asymptotically normally distributed. However, we do not make use of their adjustment procedure but use bootstrap methods to compute critical values for the null hypothesis. This procedure is described in section B.2.

\section{B.2 Bootstrap Procedure}

Since the finite-sample properties of the adjusted $\tau$ statistics are unknown and since idiosyncratic shocks may be correlated across individual regions we rely on bootstrap methods to infer critical values for the $\tau$ statistics. More precisely, we employ a nonparametric bootstrap where we resample the estimated residuals from our model. The starting point of our bootstrap approach is given by the hypothesized data generating process (DGP) under the null hypothesis

$$
\Delta q_{i, t}=\sum_{j=1}^{k_{i}} \phi_{i, j} \Delta q_{i, t-j}+\epsilon_{i, t} .
$$

Our procedure is as follows:

1. We retrieve the OLS residuals from estimating the DGP under the null hypothesis. This yields the vectors $\hat{\epsilon}_{1}, \hat{\epsilon}_{2}, \ldots, \hat{\epsilon}_{T}$, where $\hat{\epsilon}_{t}$ is the $1 x N$ residual vector for period $t$.

2. Then, we resample these residual vectors by drawing one of the possible $T$ residual vectors with probability $\frac{1}{T}$ for each $t=1, \ldots, T$.

3. These resampled residual vectors are used to recursively build up pseudoobservations $\Delta \hat{q}_{i, t}$ according to the DGP (using the estimated coefficients $\hat{\phi}_{i, j}$ ).

4. Next, we perform the Levin-Lin test (as described in section B.1) on these observations (without subtracting the cross-sectional mean). The resulting $\tau$ is saved.

5. Steps two to four are repeated 5,000 times. The collection of the $\tau$ statistics form the bootstrap distribution of these statistics under the null hypothesis. 


\section{Im-Pesaran-Shin Panel Unit Root Test}

\section{C.1 The Test Procedure}

To obtain the Im-Pesaran-Shin panel-unit root results in section 6, we proceed as follows: Let $q_{i, t}$ (with $i=1,2, \ldots, N$ and $t=1,2, \ldots, T$ ) be a balanced panel of real exchange rates consisting of $N$ individual regions with $T$ observations, respectively. Following Im et al. (2002) we start our analysis by estimating the following ADF test equation

$$
\Delta \tilde{q}_{i, t}=\alpha_{i}+\rho_{i} \tilde{q}_{i, t-1}+\sum_{j=1}^{k_{i}} \phi_{i, j} \Delta \tilde{q}_{i, t-j}+\epsilon_{i, t}
$$

for each of the $N$ individual real exchange rate series. In this equation the tilde above the variable $q$ indicates that the cross-sectional mean has been subtracted from the real exchange rate series, i.e.,

$$
\tilde{q}_{i, t}=q_{i, t}-\frac{1}{N} \sum_{j=1}^{N} q_{j, t} .
$$

As the subindex $i$ for the parameter $k$ indicates we allow the number of included lagged differences to vary across individual series. For each series the number of included lags is determined according to the general-to-specific method by Hall (1994), recommended by Campbell and Perron (1991). The maximum number of lags is set to six.

The Im-Pesaran-Shin test procedure imposes for the null hypothesis of non-stationarity the homogeneity restriction that all $\rho_{i}$ are equal across individual regions. Thus, the null hypothesis can be formulated as:

$$
H_{0}: \rho_{1}=\rho_{2}=\cdots=\rho_{N}=\rho=0 .
$$

Unlike the Levin-Lin test, however, there is no analogous homogeneity condition for the alternative hypothesis of stationarity which is given by:

$$
H_{1}: \rho_{1}<0 \cup \rho_{2}<0 \cup \cdots \cup \rho_{N}<0 .
$$

To test this null hypothesis we individually estimate equation (C.1) and retrieve for each equation the studentized coefficient $\hat{\tau}_{i}$ which is given by $\frac{\hat{\rho}_{i}}{\hat{\sigma}_{\rho_{i}}}$ (where $\hat{\sigma}_{\rho_{i}}$ denotes the standard deviation of the estimated adjustment coefficient $\rho_{i}$ ). The panel unit root test statistics $\tau_{i p s}$ is then obtained by averaging the t-values of the estimated $\rho$-coefficients, i.e.,

$$
\tau_{i p s}=\sum_{i=1}^{N} \hat{\tau}_{i}
$$


Im et al. (2002) show that this statistics is asymptotically standard normally distributed. However, we do not make use of this result (partly as it relies on the assumption that the errors $\epsilon_{i t}$ are independent across individual). The critical values reported in the main text are obtained via a non-parametric bootstrap procedure that is described in subsection C.2.

\section{C.2 Bootstrap Procedure}

Since the finite-sample properties of the Im-Pesaran-Shin test statistics $\tau_{i p s}$ might differ considerably from their asymptotic properties and since idiosyncratic shocks may be correlated across individual regions we rely on bootstrap methods to infer critical values for the $\tau_{i p s}$ statistics. As for the Levin-Lin test, we employ a nonparametric bootstrap where we resample the estimated residuals from our model. The starting point of our bootstrap approach is given by the hypothesized data generating process (DGP) under the null hypothesis

$$
\Delta q_{i, t}=\sum_{j=1}^{k_{i}} \phi_{i, j} \Delta q_{i, t-j}+\epsilon_{i, t} .
$$

Our procedure is as follows:

1. We retrieve the OLS residuals from estimating the DGP under the null hypothesis. This yields $\hat{\epsilon}_{1}, \hat{\epsilon}_{2}, \ldots, \hat{\epsilon}_{T}$, where $\hat{\epsilon}_{t}$ is the $1 x N$ residual vector for observation $t$.

2. Then, we resample these residual vectors by drawing one of the possible $T$ residual vectors with probability $\frac{1}{T}$ for each $t=1, \ldots, T$.

3. These resampled residual vectors are used to recursively build up pseudoobservations $\Delta \hat{q}_{i, t}$ according to the DGP (using the estimated coefficients $\hat{\phi}_{i, j}$ ).

4. Next, we perform the Im-Pesaran-Shin test (as described in subsection C.1) on these observations (without subtracting the cross-sectional mean). The resulting test statistic $\hat{\tau}$ is saved.

5. Steps two to four are repeated 5,000 times. The collection of the $\hat{\tau}$ statistics form the bootstrap distribution of these statistics under the null hypothesis. 


\section{CFS Working Paper Series:}

\begin{tabular}{|c|c|c|}
\hline No. & Author(s) & Title \\
\hline $2003 / 36$ & Reinhard H. Schmidt & $\begin{array}{l}\text { Corporate Governance in Germany: } \\
\text { An Economic Perspective }\end{array}$ \\
\hline $2003 / 37$ & $\begin{array}{l}\text { George W. Evans } \\
\text { Bruce McGough }\end{array}$ & $\begin{array}{l}\text { Monetary Policy, Indeterminacy } \\
\text { and Learning }\end{array}$ \\
\hline $2003 / 38$ & $\begin{array}{l}\text { James Bullard } \\
\text { In-Koo Cho }\end{array}$ & Escapist Policy Rules \\
\hline $2003 / 39$ & $\begin{array}{l}\text { Seppo Honkapohja } \\
\text { Kaushik Mitra }\end{array}$ & $\begin{array}{l}\text { Performance of Inflation Targeting Based On } \\
\text { Constant Interest Rate Projections }\end{array}$ \\
\hline $2003 / 40$ & $\begin{array}{l}\text { Athanasios Orphanides } \\
\text { John C. Williams }\end{array}$ & $\begin{array}{l}\text { Imperfect Knowledge, Inflation Expectations, } \\
\text { and Monetary Policy }\end{array}$ \\
\hline $2003 / 41$ & $\begin{array}{l}\text { Sharon Kozicki } \\
\text { P.A. Tinsley }\end{array}$ & $\begin{array}{l}\text { Permanent and Transitory Policy Shocks in an } \\
\text { Empirical Macro Model with Asymmetric } \\
\text { Information }\end{array}$ \\
\hline $2003 / 42$ & $\begin{array}{l}\text { Mordecai Kurz } \\
\text { Hehui Jin } \\
\text { Maurizio Motolese }\end{array}$ & $\begin{array}{l}\text { The Role of Expectations in Economic } \\
\text { Fluctuations and the Efficacy of Monetary Policy }\end{array}$ \\
\hline $2003 / 43$ & $\begin{array}{l}\text { William A. Brock } \\
\text { Steven N. Durlauf } \\
\text { Kenneth D. West }\end{array}$ & $\begin{array}{l}\text { Policy Evaluation in Uncertain Economic } \\
\text { Environments }\end{array}$ \\
\hline $2003 / 44$ & $\begin{array}{l}\text { Timothy Cogley } \\
\text { Sergei Morozov } \\
\text { Thomas J. Sargent }\end{array}$ & $\begin{array}{l}\text { Bayesian Fan Charts for U.K. Inflation: } \\
\text { Forecasting and Sources of Uncertainty in an } \\
\text { Evolving Monetary System }\end{array}$ \\
\hline $2003 / 45$ & Guenter W. Beck & $\begin{array}{l}\text { Nominal Exchange Rate Regimes and Relative } \\
\text { Price Dispersion: On the Importance of Nominal } \\
\text { Exchange Rate Volatility for the Width of the } \\
\text { Border }\end{array}$ \\
\hline $2004 / 01$ & $\begin{array}{l}\text { Ivica Dus } \\
\text { Raimond Maurer } \\
\text { Olivia S. Mitchell }\end{array}$ & $\begin{array}{l}\text { Betting on Death and Capital Markets in } \\
\text { Retirement: A Shortfall Risk Analysis of Life } \\
\text { Annuities versus Phased Withdrawal Plans }\end{array}$ \\
\hline
\end{tabular}

Copies of working papers can be downloaded at http://www.ifk-cfs.de 